NBER WORKING PAPER SERIES

\title{
COST OF SERVICE REGULATION IN U.S. HEALTH CARE: MINIMUM MEDICAL LOSS RATIOS
}

\author{
Steve Cicala \\ Ethan M.J. Lieber \\ Victoria Marone \\ Working Paper 23353 \\ http://www.nber.org/papers/w23353
NATIONAL BUREAU OF ECONOMIC RESEARCH
1050 Massachusetts Avenue
Cambridge, MA 02138
April 2017

We are grateful to Michael Chernew, Leemore Dafny, Joshua Gottlieb, Neale Mahoney, Magne Mogstad, Matthew Notowidigdo, Christopher Ody, Morten Olsen, Ariel Dora Stern, and GlenWeyl, as well as seminar participants at Chicago, Northwestern, and Harvard for helpful comments and suggestions. This paper combines work from Marone ("Bending the Cost Curve the Wrong Way? Evaluation of Medical Loss Ratio (MLR) Regulation in the Health Insurance Industry") that was initially conducted in parallel with that of Cicala and Lieber. All errors remain our own. The views expressed herein are those of the authors and do not necessarily reflect the views of the National Bureau of Economic Research.

NBER working papers are circulated for discussion and comment purposes. They have not been peerreviewed or been subject to the review by the NBER Board of Directors that accompanies official NBER publications.

(C) 2017 by Steve Cicala, Ethan M.J. Lieber, and Victoria Marone. All rights reserved. Short sections of text, not to exceed two paragraphs, may be quoted without explicit permission provided that full credit, including $(\mathcal{C}$ notice, is given to the source. 
Cost of Service Regulation in U.S. Health Care: Minimum Medical Loss Ratios

Steve Cicala, Ethan M.J. Lieber, and Victoria Marone

NBER Working Paper No. 23353

April 2017, Revised July 2017

JEL No. I10,L5,L98

\begin{abstract}
A health insurer's Medical Loss Ratio (MLR) is the share of premiums spent on medical claims. The Affordable Care Act introduced minimum MLR provisions for all health insurance sold in fully-insured commercial markets, thereby capping insurer profit margins, but not levels. While intended to reduce premiums, we show this rule creates incentives analogous to cost of service regulation. Using variation created by the rule's introduction as a natural experiment, we find claims costs rose nearly one-for-one with distance below the regulatory threshold: $7 \%$ in the individual market, and $2 \%$ in the group market. Premiums were unaffected.
\end{abstract}

\author{
Steve Cicala \\ Harris School of Public Policy \\ University of Chicago \\ 1155 East 60th Street \\ Chicago, IL 60637 \\ and NBER \\ scicala@uchicago.edu \\ Ethan M.J. Lieber \\ University of Notre Dame \\ Notre Dame, IN 46556 \\ elieber@nd.edu
}

\author{
Victoria Marone \\ Northwestern University \\ Evanston, IL 60208 \\ marone@u.northwestern.edu
}




\section{Introduction}

One goal of the Patient Protection and Affordable Care Act (ACA) was to reduce the cost of health insurance. To that end, the law instituted minimum requirements on the share of premiums that commercial insurers must spend on medical claims. This share is known as the Medical Loss Ratio (MLR), and is a measure of the actuarial fairness of insurance. ${ }^{1}$ This paper formalizes the connection between this type of mandated actuarial fairness in insurance markets and cost of service regulation, and then uses recent federal regulatory changes to estimate the distortion such a policy induces in the provision of health insurance. We find that rather than reducing premiums, insurers increased their claims costs nearly one-for-one with their distance below the regulatory threshold.

Some form of MLR regulation has existed at the state level since 1980, but was typically used as a tool to assess and compare insurer value (America's Health Insurance Plans, 2010). State insuance commissioners would use projections of costs to approve premium increases based on the MLR, but did not enforce regulations based on the ex post realization of costs (Harrington, 2013). The ACA standardized and extended this regulation to the federal level, becoming effective for the commercial, fully-insured market in January $2011 .^{2}$ Specifically, on a state by state and segment by segment basis, insurers are required to maintain a MLR of at least $80 \%$ in the individual and small group market segments and $85 \%$ in the large group market segment (it has become colloquially known as the ' $80 / 20$ rule'). A similar regulation also went into effect for the Medicare Advantage market beginning in 2014.

In an important departure from prior state MLR regulations, federal MLR regulation requires insurers to issue rebates to customers based on their realized MLR. As an example, if an insurer collects $\$ 100$ in premiums in the individual market, but spends only $\$ 79$ paying medical claims that year, they are required to write a $\$ 1$ check to policy holders. This regulation was indeed binding for many insurers, with over $\$ 1$ billion in rebates issued to consumers in 2011. MLRs have risen (and rebates have fallen) in subsequent years, with an additional $\$ 1.8$ billion rebated in total between 2012-2015. The Centers for Medicare and Medicaid Services (CMS), which administers the rule, routinely cites rebates and increased MLRs as evidence of the program's

1 This regulation was established by Section 2718 of the ACA, entitled "Bringing Down the Cost of Health Coverage." The regulatory definition of MLR also has adjustments for taxes, regulatory fees, and insurer expenditures on health plan "quality," which we discuss in greater detail below.

2 The market for "fully-insured" health insurance products is distinct from the market for "self-insured" products often purchased by medium and large employers. In the former "fully-insured" case, a health insurance company bears the financial risk of adverse health events and actually provides the risk pooling function; in the latter "self-insured" case, the health insurance company merely sells its services as as claims administrator and does not bear any financial risk on behalf of the purchaser. Self-insured products are not subject to MLR regulation, nor many other regulations. Fully-insured products account for roughly $58 \%$ of the private commercial health insurance market as of 2013, by covered lives (Henry J. Kaiser Family Foundation and Health Research \& Educational Trust, 2015). Non-profit insurers were also exempt from the regulation. 
success, calculating savings by applying pre-2011 MLRs to observed claims costs to estimate how much higher premiums would have been if not for the regulation (The Centers for Medicare \& Medicaid Services, 2014a). We use the imposition of this binding regulation as identifying variation to estimate the effects of minimum MLR regulation-thus the magnitude of rebates (which are small relative to the industry) demonstrate the opportunity to estimate the response to MLR regulation, but does not bound its overall importance in determining costs in the health insurance sector.

At its simplest level, this paper observes that our hypothetical insurer with $\$ 100$ in premium revenue and $\$ 79$ in claims finds it must bear the full administrative cost of keeping expenditures below $\$ 80$, but reaps none of the rewards. That is, minimum MLR requirements encourage higher costs, not lower. We draw the direct parallel between MLR regulation and cost of service regulation, and show empirically that the $80 / 20$ rule has, indeed, substantially increased insurers' medical expenditures. ${ }^{3}$ While perhaps obvious ex post, this connection has not been established (nor estimated) to date.

The paper therefore contributes to our understanding of both firm response to regulation in the health care sector, and to cost of service regulation more broadly. Recent empirical work has shown the importance of Averch and Johnson (1962)-type bias in input choices both in health care (Acemoglu and Finkelstein, 2008) in addition to the electricity sector (Cicala, 2015; Fowlie, 2010). In our setting, the regulatory instrument is even more blunt than favoring one input over another, and the regulator has no authority to deny reimbursement for 'imprudent' expenditures. It has also been shown that both providers and insurers respond to such economic incentives: doctors and hospitals change how they treat patients in response to Medicare reimbursement incentives, (Einav et al., 2017; Clemens and Gottlieb, 2014), drug makers charge higher prices to more price-inelastic customers (Duggan and Scott Morton, 2006), and insurers free-ride on Medicare reimbursement schedules to economize on negotiation costs (Clemens and Gottlieb, 2017; Clemens et al., 2015). Such responses have not been studied in the context of minimum MLR regulations, where existing work has focused on its connection to markups, and the response of firms in imperfectly competitive markets to such regulation, holding costs fixed (Starc, 2014; Ericson and Starc, 2015; Karaca-Mandic et al., 2015; Abraham and KaracaMandic, 2011). ${ }^{4}$

We model the behavior of a monopolistic insurer offering coverage of a fixed health shock

3 We note the important distinction here between insurers' medical expenditures and total medical expenditures, where the difference is accounted for by out-of-pocket costs. While we find that insurers' medical expenditures have risen as a result of MLR regulation, we do not have strong evidence on its effects on total medical spending.

4 Harrington (2013) qualitatively connects minimum MLRs to economic regulation broadly, and reviews a number of potential unintended consequences-in particular the asymmetry created when rebates limit the upside risk to insurers. 
at a chosen price per dollar of insurance. We show that the imposition of an MLR constraint yields a model that is identical to that of Averch and Johnson (1962), but with a single input. We then endogenize the cost of insuring the health shock by allowing the insurer to also choose how much effort to exert to keep costs down, in the spirit of Laffont and Tirole (1993). We show that minimum MLR regulations are predicted to curtail cost-reducing effort and increase medical expenditures, while the impact on premiums is ambiguous (and depends on the relative curvatures of the demand and cost-reducing effort functions).

We measure the impact of the $80 / 20$ rule on MLRs, medical claims per life-year, and premiums per life-year using annual data from 2005-2013 from the National Association of Insurance Commissioners (NAIC). This organization standardizes state-level reporting of insurer finances and formed the basis of reporting requirements that were adopted as part of federal MLR regulation. These data allow the construction of a panel both preceding and after the implementation of federal MLR regulation at the unit of observation at which the regulation applies: for each insurer, in each market segment, in each state, for each year. ${ }^{5}$

We use a difference-in-difference framework that compares changes in outcomes over time between insurers with historically low MLRs versus those who were persistently already in compliance with the rule before it took effect. We show that this regulation is associated with an abrupt increase in MLRs for "treated" firms that is approximately one-for-one with their distance from the mandated MLR minimum. This increase was accomplished (particularly after a year or two of adjustment) almost entirely by increases in medical claims expenditures. Our preferred estimates show a $7 \%$ increase in claims in the individual market for firms that were previously out of compliance; in the group market, we estimate a $2 \%$ increase in claims, though the latter estimate is imprecise. These increases occur with a sharp break from historical trends. We find little evidence of a reduction in premiums in either the individual or group markets. Consistent with our model of cost-reducing effort, we find suggestive evidence that insurers cut administrative spending when the regulation was binding, but that the magnitudes of the changes in administrative costs are small relative to the magnitude of changes in claims costs (and thus simple "relabelling" of administrative costs as claims costs cannot explain our results).

There are two main challenges to interpreting our results as causal estimates of the impact of the $80 / 20$ rule. First, we cannot actually observe treatment, i.e., whether a firm's unregulated MLR would have been beneath the minimum threshold, since we only observe realized MLRs. Because the majority of a firm's MLR variation is persistent (and to avoid issues of mean-reversion), we use the five-year average MLR preceding the ACA to measure treatment intensity, and show general robustness to the width of this window. This is a noisy proxy

5 Federal MLR regulation distinguishes between the large and small group market segments, but the NAIC data reports these segments jointly. Thus, our analysis of the group market looks at these two market segments together; we discuss this in greater detail below. 
for true treatment, and therefore adds attenuation bias to our estimates. Second, MLRs are not randomly assigned, but reflect endogenous decisions of firms in response to demand, market structure, regulations, provider negotiations, etc. We assume that prior compliance with the rule before its implementation means that no policy-induced changes in behavior occurred among firms with high MLRs, and that the other regulations did not fall differentially upon high- versus low-MLR firms. The absence of diverging pre-trends and robustness to alternative specifications lends credibility to these assumptions. At a minimum, we show there has been a stark, abrupt relative change in outcomes for low-MLR firms following the implementation of the ACA rule.

It is important to note at the outset that while our results show impacts of MLR regulations that are sharply divergent from their original intention (lowering premiums), it is difficult to make a statement about net welfare. To the extent that higher claims result from additional care, the presence of moral hazard in the consumption of insured health care would suggest that such costs exceed policyholder willingness to pay for them. On the other hand, if insurers were inefficiently restricting the actuarial value of plans, this expansion in claims has a positive net value to society insofar as it moves equilibrium toward the intersection of the marginal cost and marginal willingness to pay for insurance. Even if the entire increase in claims costs were due to higher provider prices with no change in quantities (a transfer to providers), one would still need to account for the benefit to insurers of less price-reducing negotiation effort. Instead of making net welfare statements, our goal in this paper is to take a first step in characterizing the nature (and magnitude) of the problem so that the tools developed elsewhere for such settings might be brought to bear in the future. ${ }^{6}$

The paper is organized as follows: in the next section, we provide background on minimum MLR regulation and present descriptive evidence of its impact on insurers to motivate our estimation strategy. The third section demonstrates the equivalence of this rule with cost of service regulation and derives theoretical predictions of its effect on claims costs and premiums. The fourth section describes the data, and the fifth details the estimation strategy. The sixth section presents the results, and the final section concludes.

\section{Background and Motivating Evidence}

MLR regulation was only one of many systemic changes to the health insurance industry set in motion by the ACA, which was passed on March 23, 2010. As we are going to attempt to disentangle the direct effects of MLR regulation, it is important to document other potentially

\footnotetext{
6 See Laffont and Tirole (1993), for example, for a comprehensive treatment.
} 
confounding factors. The most important changes made in the individual and small-group insurance markets were the establishment of the public health insurance exchanges, a near total ban on individual risk rating, the individual health insurance mandate, and the creation of a set of Essential Health Benefits (EHBs) that plans must cover. These changes fundamentally altered the business of writing individual and small-group insurance policies, and were implemented in $2014 .^{7}$ As such, we end our study period in $2013 .^{8}$

There were, however, a number of provisions in the ACA that went into effect at the end of 2010 or the start of 2011 . Those changes which were likely to have affected the private, fullyinsured health insurance market are the extension of coverage of dependents up to the age of 26, the elimination of cost sharing for a set of preventive care procedures (e.g., mammograms), the prohibition on lifetime limits on coverage, and the creation of a national high-risk pool. For example, research on the coverage of dependents up to the age of 26 has found that this provision reduced uninsurance levels and led to somewhat higher insurance premiums (Antwi et al., 2013; Depew and Bailey, 2015). Section VI discusses how these contemporaneous policy changes affect the interpretation of our results.

Prior to the ACA, 29 states had some form of MLR regulations on the books, but the regulations do not appear to have been binding on realized MLRs. In some cases, states had thresholds that were very low; the median MLR threshold among states with some regulation was only 0.65. Even where the MLR thresholds were higher, states often lacked the ability to enforce the regulation. For example, in states where the MLR threshold was 0.75 or higher in the individual market, more than 40 percent of life-years were in plans that did not meet the requirement in 2010. Harrington (2013) explains this apparent non-enforcement in the context of the rate hearings process: state commissioners would use projections of costs to approve premium increased based on the MLR, but did not enforce regulations based on the ex post realizations of costs.

Regulation of minimum MLR thresholds was brought to the federal level as part of the ACA. These thresholds are not enforced on a plan-by-plan, nor an insurer-by-insurer, basis. Instead, the insurer aggregates all of its business within a given state, market segment, and year, and the MLR realized over this block of business must meet the MLR threshold. The threshold is 0.80 for the individual and small group markets and 0.85 for the large group market. In the year immediately preceding the implementation of MLR regulation, more than 52 percent of

\footnotetext{
7 These regulations applied to all new plans offered as of 2014, but plans already in existence were given "grandfathered" status and allowed to remain unchanged. Insurers may have differed in the extent to which they utilized these "low value" health plans prior to the ACA, and the effect may play out over time as these "grandfathered" plans are phased out gradually. EHB requirements were put into place in 2014.

8 Our discussion of ACA provisions is based primarily upon information from Henry J. Kaiser Family Foundation (2013).
} 
consumers insured in the individual market were in plans with an MLR below $0.80 .{ }^{9}$ Beginning in 2011, if an insurer fell below the applicable MLR threshold, it had to send rebates to its policyholders. ${ }^{10}$

Figure 1 shows the cumulative density function (CDF) of MLRs in the individual market for the years 2005 through 2010 as well as for 2013. The gray lines show the CDFs for each year from 2005 through 2009. Although there is some variation from year to year, the CDFs remain fairly similar over this period, and 2010 (the blue line) does not appear to be systematically different from the other pre-ACA years. However, by 2013, the distribution of MLRs has moved to the right as MLRs increased, but not evenly throughout the distribution. The increase in MLRs is heavily concentrated among firms with MLRs below the federal 0.80 threshold (denoted by the vertical red line). As mentioned previously, in 2010, 52 percent of lives were covered by insurers with MLRs below the regulated threshold, but by 2013, only 30 percent of covered lives were below the threshold. One can also note the sharp jump in density in the neighborhood of the threshold in 2013, while prior distributions are far less concentrated around this point. Those insurers below the threshold in 2013 were required to pay rebates.

The corresponding distribution for the group market is somewhat less informative because prior to the ACA, the NAIC did not collect information separately for the small group and large group market segments. This creates measurement error in our aggregated data. A firm could be far below the ACA threshold in one market segment and above the threshold in the other. The degree to which we expect to see a response in the aggregate data depends upon how much of the firm's group business was in the segment below the threshold, something we do not observe. With that caveat in mind, Figure 2 presents the CDFs of MLRs for the aggregate group market from 2005 through 2010 and for 2013.

Comparing 2010 and 2013, there appears to be a small increase in MLRs at the low end of the distribution. Because 0.80 is the minimum threshold set by the ACA, it is quite likely that firms with an aggregate MLR below 0.80 are below their relevant threshold. ${ }^{11}$ Above 0.80 , there is very little difference between the 2010 and 2013 distributions. This is consistent with the changes observed in the individual market, which were that the distribution of MLRs appears to have been shifted to the right for low MLR firms, but there was very little movement above

9 Unfortunately, we are not able to separate insurer's small and large group business in the data used for this calculation. As a result, we can not directly calculate the fraction of consumers in group plans in 2010 with MLRs below the ACA group thresholds. However, we can bound this fraction. Using a threshold of 0.80 (correct for the small group market), we find that 20 percent of consumers in the group market were in plans below the ACA threshold; using the threshold of 0.85 (correct for the large group market), approximately half of the consumers would have been in plans that did not meet the threshold.

${ }^{10}$ Rebates are calculated such that after the insurer has paid out the rebates, and the rebates are added to the MLR numerator, its MLR would be equal to the regulated threshold.

11 There are adjustments to the ACA MLR threshold that can reduce the target level further. These are discussed in Section IV 
Figure 1: Distributions of MLRs in the Individual Market Over Time

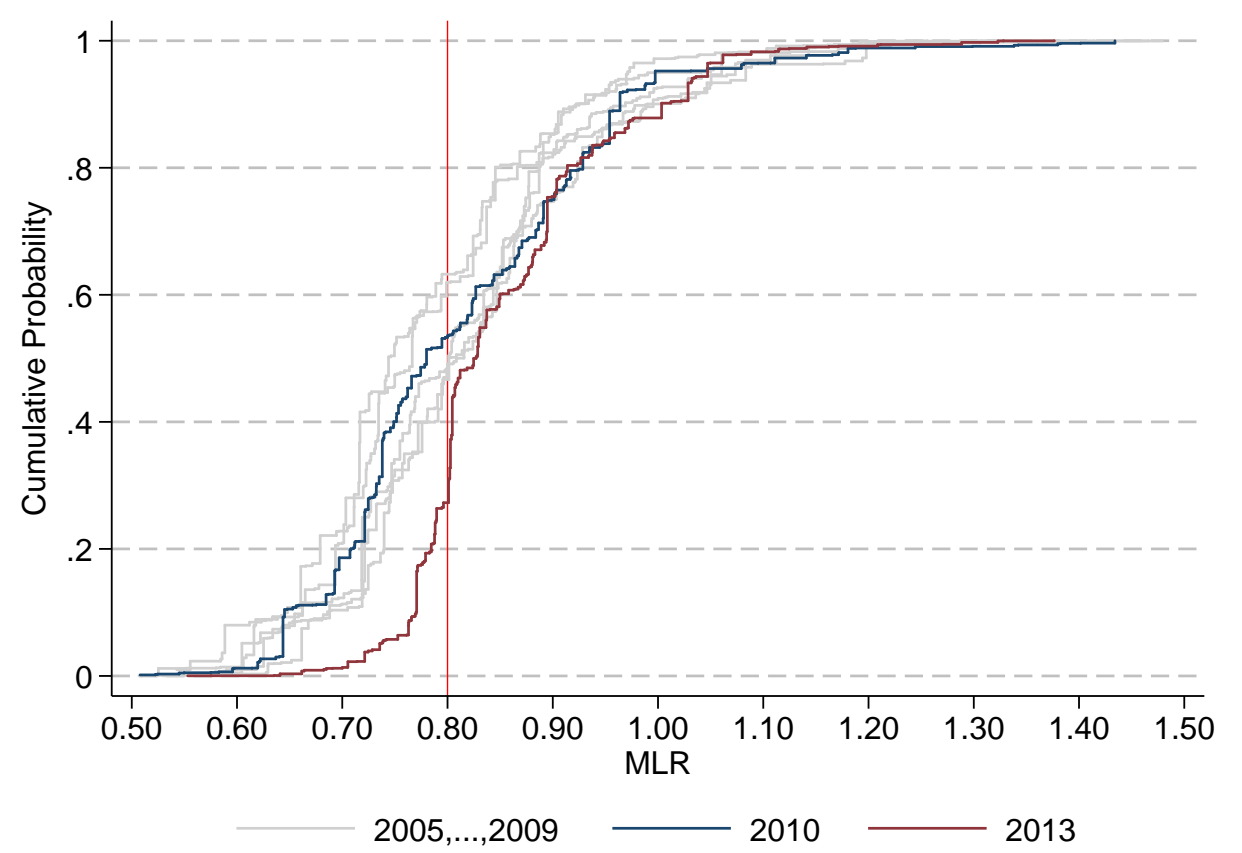

Note: Each CDF represents the fraction of life-years (not firms) at a particular MLR level, where MLR is defined as claims over premiums. The figure is based on NAIC data (see Section IV for details)

the MLR thresholds. That said, the year-to-year variance in group market MLRs and concerns about measurement error mentioned above prevent us from inferring too much from this figure on its own.

By the end of 2015 , insurers had paid nearly $\$ 2.8$ billion in rebates to consumers as a result of not meeting the MLR thresholds. Figure 3 shows these rebates by market segment and year, where the left panel shows total rebates, and the right panel shows rebates per life-year of enrollment (i.e, per enrollee). We combine the small- and large-group market segments into one "group" market to be consistent with our later analysis. In 2011, $\$ 400$ million in rebates were paid in the individual market and $\$ 700$ million in the group market. Significantly lower rebates were paid in subsequent years. Rebates in 2012 were approximately half of those paid in 2011, and in 2013, they were approximately one-third of 2011 rebates. There appears to have been slight increases after the exchanges came online in 2014, which was likely the result of significant uncertainty around the health of the population entering the market.

Much of the relative magnitude of total rebates between the individual and group markets can be attributed to total enrollment: in 2011, 11.5 million people obtained coverage in the individual market and 71.4 million in the group market. ${ }^{12}$ On a per life-year basis, however,

\footnotetext{
12 Authors' calculation based upon the CMS data (see Section IV for details).
} 
Figure 2: Distributions of MLRs in the Group Market Over Time

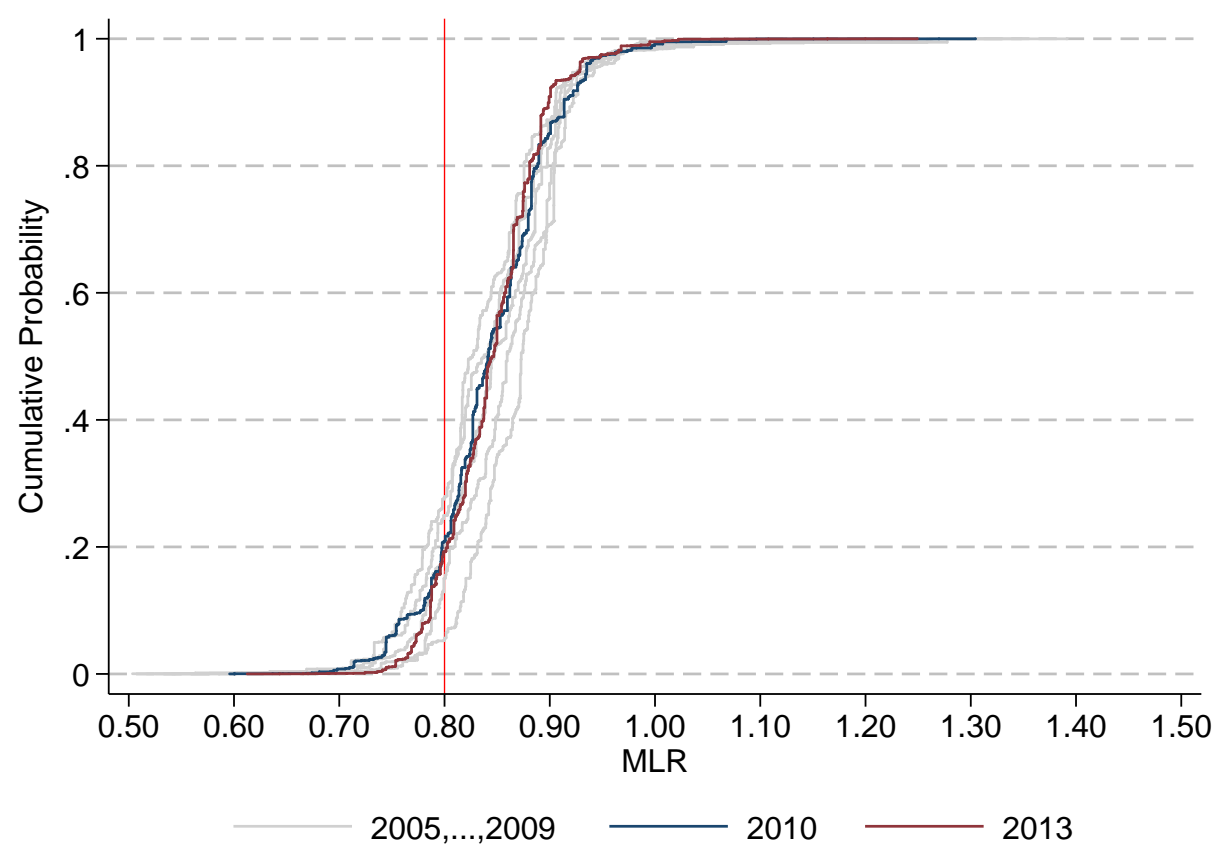

Note: Each CDF represents the fraction of life-years (not firms) at a particular MLR level, where MLR is defined as claims over premiums. The figure is based on NAIC data (see Section IV for details)

rebates in the individual market are far greater, reflecting the lower MLRs in this market segment. In 2011, insurers in the individual market paid approximately $\$ 35$ in rebates per enrollee; in the group market, the analogous number is $\$ 10$. Rebates have converged over time between markets on a per-enrollee basis.

While the magnitude of the rebates is small relative to the overall size of the market for health care, they are providing a measure of the amount of identifying variation that exists, not the potential impact of MLR regulation on the market as a whole. Many firms might have maintained high MLRs as a result of competitive forces, but it is also possible that the mechanism that we seek to measure was already at work on a forward-looking basis during state rate hearings before the ACA. These rebates, particularly those in 2011, are a measure of what variation in exposure to the regulation exists for estimating the effect of MLR regulation, not its sum total impact. The reduction in rebates over time suggests that firms made changes to bring their business into compliance with the regulated MLR minima.

There is a small but growing literature on the impacts of the ACA's MLR regulation (Abraham et al., 2014; McCue et al., 2013; McCue and Hall, 2015; Clemans-Cope et al., 2015). These papers use data from 2010-2012 and have found that MLRs increased, particularly in the individual 
Figure 3: Rebates Paid by Year and Market Segment
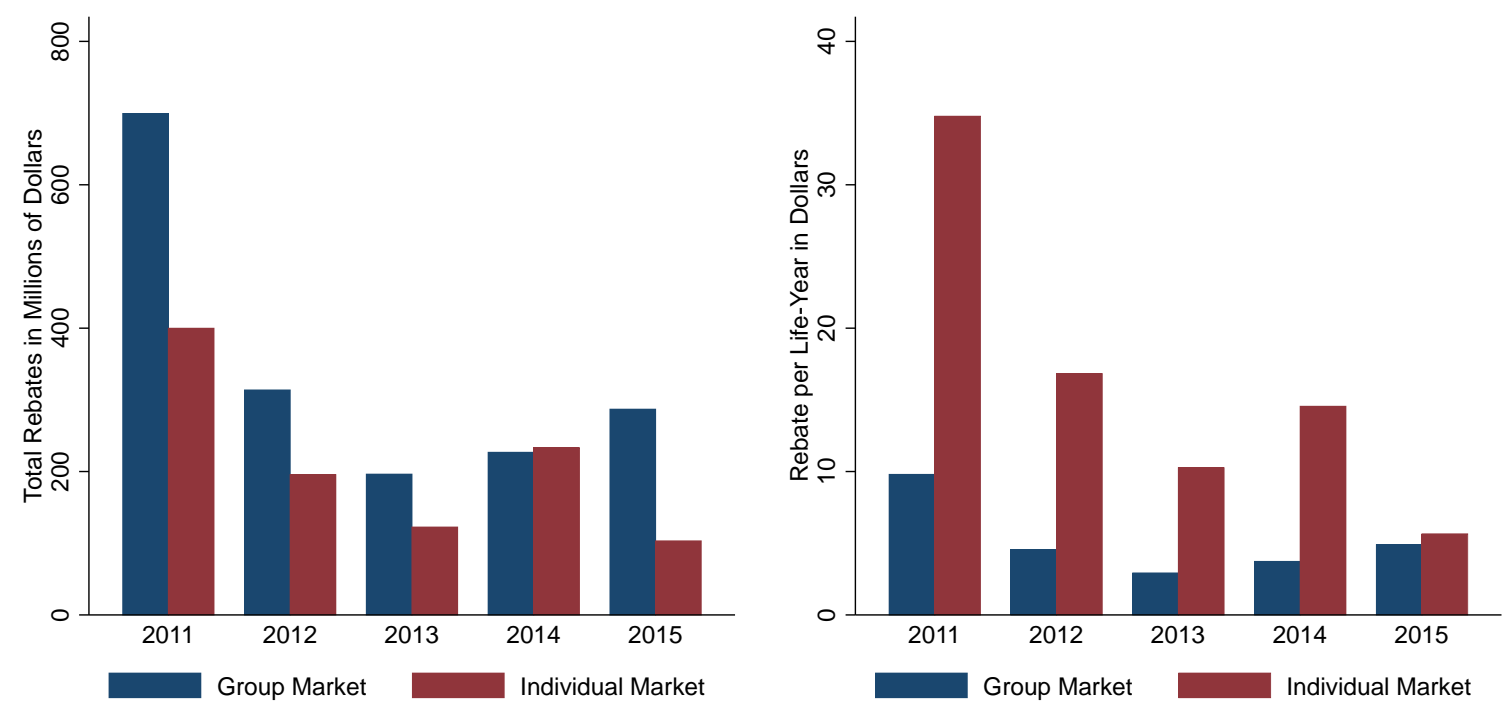

Note: Rebates are tabulated from CMS data, combining large and small group market segments to form the "Group Market" (see Section IV for details).

market and for for-profit insurers. ${ }^{13}$ While McCue et al. (2013) and McCue and Hall (2015) study the reduced form impact of the change in regulation on outcomes, Abraham et al. (2014) and Clemans-Cope et al. (2015) study outcomes as a function of a firm's 2010 MLR. Because these studies rely on a single year of data before the regulations went into effect, it is not clear whether the estimated changes are reflecting other underlying trends in the insurance market or are causal impacts of the regulation. Our work complements these studies by explicitly linking the regulation to the theoretical literature on cost of service regulation and using data from a much longer time frame in combination with a research design that allows us to address concerns about underlying trends and mean reversion.

\section{Minimum MLRs as Cost of Service Regulation}

We next present a model of insurer behavior subject to MLR regulation to derive predictions of the industry's response. Moreover, we show minimum MLR requirements are equivalent to cost of service regulation. To demonstrate this equivalence, we consider the decision of a monopolistic insurance provider choosing a price $p$ per dollar of coverage against a negative health shock $H$ that occurs with probability $r$ in a homogenous population. Consumers choose a level of coverage $q \in[0, H]$ that pays off $q$ dollars if they experience the health shock, and have 13 These studies have also explored the impacts on a number of financial outcomes such as administrative costs,
profits, and quality improvement expenditures. 
an elastic demand for coverage $q(p)$. The level of coverage $q$ chosen by the consumer determines the actuarial value of the plan,equal to $\frac{q}{H}$. In this setting, the actuarially fair price per dollar of insurance would be $p=r$, at which the insurer would make zero profits in expectation. Without any regulatory constraints the monopolist would maximize expected profits

$$
\max _{p} p q(p)-r q(p)
$$

with the usual results. MLR regulation requires that expenditures on medical care (expressed here as the insurer's expected liability, $r q(p))$ exceed some share of premium revenues, so that $\frac{r q(p)}{p q(p)} \geq k$ for some $k \in(0,1)$. Under MLR regulation, the firm therefore faces the objective function

$$
\max _{p} p q(p)-r q(p)+\lambda[r q(p)-k p q(p)]
$$

Note that this constrained maximization is equivalent to the Lagrangian of Averch and Johnson (1962), equation (7), but with a single input, and the probability of the health shock playing the role of the marginal cost of the input. When the constraint binds, this yields

$$
p\left(1+\frac{1}{\varepsilon^{D}}\right)=\frac{1-\lambda}{1-k \lambda} r<r
$$

The relationship between the optimal MLR and the inverse of the elasticity of demand makes clear that this is a markup regulation for all intents and purposes. The more inelastic is demand, the higher the optimal markup (and lower the MLR) for the unconstrained monopolist, and the more heavily behavior will be impacted by a minimum MLR requirement. Compared with the unconstrained monopolist, MLR regulation in this framework leads to expanded coverage (i.e., higher actuarial value of plans), as well as a lower price per dollar of insurance (i.e., a lower price per dollar of covered potential loss) for consumers. While MLR regulation reduces the monopoly distortion, it may not necessarily improve welfare in the presence of the other market imperfections that are ubiquitous in this sector. In any case, it certainly does not lead to a reduction in the insurer's health care expenditures: the elastic demand implied by the first order condition leads to an increase in total premium revenue $(p q(p))$, and total claims paid $(r q(p))$ increase with the more complete coverage.

Having shown the equivalence of minimum MLR regulation with cost of service regulation, we now introduce the notion that the insurer decides how much effort, $e$, to exert in order to keep marginal costs down. That is, instead of just paying some share of the cost of the exogenous health shock, insurers participate in the the determination of the prices paid for healthcare services. In practice, this is a more accurate description of U.S. health insurance, in which insurers establish networks of doctors and hospitals with whom prices are negotiated (Dranove et al., 1993; Ho, 2009; ?). Using the framework of Laffont and Tirole (1993), this 
effort is measured in dollars of reduced marginal costs, which are $c=\beta-e$ where $e \in[0, \beta]$. Effort is treated as a fixed cost, and reduces profits according to a convex function $\psi(e)$, where $\psi^{\prime}(e)>0, \psi^{\prime \prime}(e)>0 .{ }^{14}$ The insurer therefore solves

$$
\begin{array}{ll}
\max _{p, e} \quad & {[p-(\beta-e)] q(p)-\psi(e)} \\
\text { s.t. } \quad & (\beta-e) \geq k p
\end{array}
$$

where $k$ continues to denote the minimum allowable MLR. Supposing the constraint binds, one can substitute in for price to solve an unconstrained objective function in effort. This yields the first order condition:

$$
q(p)+p q^{\prime}(p)=-\frac{k}{(1-k)} \psi^{\prime}(e)
$$

The following result is proven in Appendix A:

Proposition 1 Suppose the conditions necessary for (3) to be concave hold, and denote $\left(p^{M}, e^{M}\right)$ the monopolist's optimal price per dollar of coverage and effort, respectively, when the constraint does not bind. Then the optimal level of effort under MLR regulation $k, e^{R}(k) \leq e^{M}$, with strict inequality if the regulation binds.

Differentiating the binding regulatory constraint, the impact of a marginal increase in $k$ on the price per dollar of coverage is

$$
\frac{d p}{d k}=-\left(\frac{1}{k}\right)\left[p+\frac{d e}{d k}\right]
$$

This shows that in the absence of moral hazard's impact on the insurer's effort, the immediate effect of the MLR regulation is to reduce the price of a dollar of insurance (though, again, this causes an increase in total premiums due to the elastic demand for insurance). The ability to decide how hard to work to reduce marginal costs, however, erodes this effect, as $\frac{d e}{d k}<0$ (included in the proof of Proposition 1). If effort is sufficiently responsive (i.e., if the effort function $\psi(e)$ is not too convex relative to the curvature of premium revenues), an increase in the minimum allowable MLR will be accompanied by an increase in the price per dollar of insurance. Thus the impact on total premium revenues (and the comprehensiveness of coverage) is ambiguous.

The impact of MLR regulation on total claims costs depends on the potentially offsetting effects of higher marginal costs of providing insurance due to reduced effort and changes in the

14 Spending on effort in this setting can be appropriately thought of as spending on administrative costs, which detract directly from profits, and do not enter the numerator of MLR. 
level of coverage purchased $q(p)$. The second order condition for (3) is nonetheless sufficient to ensure that total claims rise, also proven in Appendix A:

Proposition 2 Retaining the assumption that the solution to (3) is a maximum is sufficient to ensure that total claims under minimum $M L R$ regulation, $C^{R}(k) \equiv\left(\beta-e^{R}(k)\right) q\left(p^{R}(k)\right) \geq$ $C^{M}$, the total claims under unconstrained monopoly, with strict inequality when the regulation binds.

This model makes strong predictions about the impact of minimum MLR regulation on claims costs, but abstracts away from several important features of insurance and health care markets to focus on parallels with cost of service regulation. Two additional margins of complexity strike us as promising for further study. First, insurers face demand uncertainty when setting premiums and negotiating provider prices. Thus, MLR regulation may affect the behavior of insurers for whom the regulation is non-binding, even in expectation, because they have optimized over the range of realizations of the demand distribution for which the regulation would bind. The law of large numbers implies this consideration would be more salient for smaller insurers than large ones, who face less uncertainty. Second, this model abstracts from consumer heterogeneity, a key focus of modern health economics research. One could imagine that another method by which to raise MLR could be to reduce screening effort aimed at avoiding high-cost consumers, thus expanding the cost base. The framework presented here does, however, provide a foundation to guide our empirical analysis of the impact of minimum MLR regulations on claims, utilization, and premiums per life-year, to which we now turn.

\section{Data}

In this section, we describe the sources of data used in our empirical analysis, discuss the sample restrictions used to create our analysis datasets, and present summary statistics overviewing the data.

\section{Description of Data}

The main source of data we use is from the National Association of Insurance Commissioners (NAIC), which is a standard-setting and regulatory support organization governed by insurance regulators from each state. As part of its mandate to coordinate regulatory oversight, the NAIC collects and publishes operational data from insurance companies. The data used in this study comes from the health insurance Exhibit of Utilization, Premiums, and Enrollment files, which 
include data on enrollment, claims expenses, and premiums written. These data are currently available for all health insurers by state and market segment between 2001 and $2014 .{ }^{15}$ The market segments we will use in our analysis are the individual segment and the group segment. The NAIC data prior to 2011 does not distinguish between the small group (employer groups under 100 people) and large group (employer groups over 100 people) market segments; thus, we will pool the small and large group segments together throughout our analysis. We use this data for years 2005-2013, as reporting rule changes create compositional shifts during the 2001-2004 period, and major non-MLR regulatory changes begin in 2014 (described in Section II).

The second data source we use is a regulatory database maintained by the federal government. In order to implement the myriad changes set in motion in 2010, the ACA gave a new regulatory mandate to the Centers for Medicare and Medicaid Services (CMS), with the goal of coordinating and overseeing the major reforms in the health insurance industry. ${ }^{16}$ As part of this effort, CMS implemented its MLR enforcement system in 2011 by setting new data reporting requirements for health insurers and collecting these data into a new regulatory database. This database contains detailed financial information about health insurers across different market segments (individual, small group, and large group) at the state level and is currently available for 2011-2015. Among many other measures, this data contain enrollment, insurer MLRs, rebate payments, administrative costs, health improvement expenses, medical claims costs, and premium revenue by insurer, state, and market segment. To help insurers (and the government) prepare for this administrative burden, NAIC introduced the Supplemental Health Care Exhibit (SHCE) in 2010, which we append to the CMS database to provide us with a single year of pre-ACA data on these more detailed outcomes. We also use the CMS data to present the magnitudes of MLR rebate payments, and show how they have changed between 2011-2015.

From the NAIC data, we create an unbalanced panel dataset at the market segment-insurerstate $(i)$ by year $(t)$ level, and define insurer MLR as follows: ${ }^{17,18}$

$$
M L R_{i t} \equiv \frac{\text { Claims }_{i t}}{\text { Premiumsit }}
$$

${ }^{15}$ A notable omission from the NAIC datasets are the majority of insurers in California, which follow different reporting requirements and report directly to the state as opposed to the NAIC.

${ }^{16}$ In fact, an entire new regulatory entity was created under the umbrella of CMS, named the Center for Consumer Information and Insurance Oversight (CCIIO). For simplicity, we will refer to this just as CMS.

17 Note that an "insurer" as defined here is a unique reporting entity within a state, not a unique insurer "group" within a state. For example, LifeWise Health Plan of Washington is owned and operated by Premera Blue Cross, but reports to the NAIC under a separate licensing number, thus LifeWise and Premera are considered different insurers for the purposes of this analysis. Additionally, insurers commonly report their HMO business separately from the rest of their business, and thus these are treated separately.

18 The field used to define Claims is Claims Incurred: "Amount incurred for provision of health services;" the field used to define Premiums is Premiums Earned: "Health premiums earned." 
The MLR calculated for 80/20 compliance is also a function of an insurer's "Quality Improvement Expenditures," which are allowed to enter the numerator of the MLR in order not to discourage spending on quality. Expenses that can fall into this category are specifically designated by the regulator as "activities that are likely to improve health outcomes, prevent hospital readmissions, improve patient safety and reduce medical errors, and increase wellness and health promotion" (The Centers for Medicare \& Medicaid Services, 2014b). Additionally, insurers are allowed to make deductions from the MLR denominator for taxes and regulatory fees. We cannot observe these additional items in the pre-period and therefore do not use them in our calculation of insurers' MLR. Both of these omissions will bias our calculated insurer MLRs downwards. This will have the effect of attenuating our estimates by classifying some insurers as persistently below the minimum threshold even if they were in compliance once these adjustments were made (see Section $\mathrm{V}$ for more details).

To arrive at the final analysis dataset, we censor outlier observations with MLRs below the 1st and above the 99th percentiles, exclude observations with missing or negative data in key fields (claims, premiums, enrollment), and exclude insurer observations with fewer than 1,000 covered lives. ${ }^{19}$ The majority of outlier observations are those for which the insurer had fewer than 1,000 covered lives, so the restrictions are highly overlapping. Geographically, we exclude observations from California (for reasons noted above) and U.S. territories. We also exclude a handful of observations manually that are clearly data errors. ${ }^{20}$ We also omit insurers present in the NAIC data that are not present in the CCIIO data, to ensure we are studying only insurers that were subject to MLR regulation. Finally, given that our identification strategy relies on determining whether an insurer is likely to be directly affected by MLR regulation by examining their pre-period MLRs, we limit to insurers with at least one year of pre-period (2010 or earlier) data.

\section{Summary Statistics}

As a graphical summary of our data, Figure 4 presents the cumulative growth of average premiums and claims over our analysis period: 2005-2013. Premiums and claims are expressed on a per-person, per-month basis, as "Per-Member-Per-Month" (PMPM) values. ${ }^{21}$ Additionally, means are enrollment-weighted to reflect the experience of the average enrollee, as opposed to the average insurer. In the group market, average claims and premiums in 2005 were $\$ 205$ and $\$ 247$, respectively. In the individual market, average claims and premiums in 2005 were $\$ 145$

191000 lives in the threshold for an insurer to be considered "credible" and to be subject to MLR regulation at all.

${ }^{20}$ A list of these errors is available from the authors upon request.

${ }^{21}$ As health insurance premiums are typically paid on a monthly basis, it is standard to express values in this way. 
and $\$ 185$, respectively. Growth in both claims and premiums has been substantial over this time period, with higher levels and slightly faster growth in the group market, where higher risk individuals can pool through their employer rather than be priced out, as may happen in the individual market. This figure also makes clear that the variation among insurers used in this paper is unlikely to have had a noticeable impact on overall mean outcomes, as historical trends have largely persisted unabated at the aggregate level.

Figure 4: Cumulative Growth of Claims and Premiums by Market Segment: 2005-2013
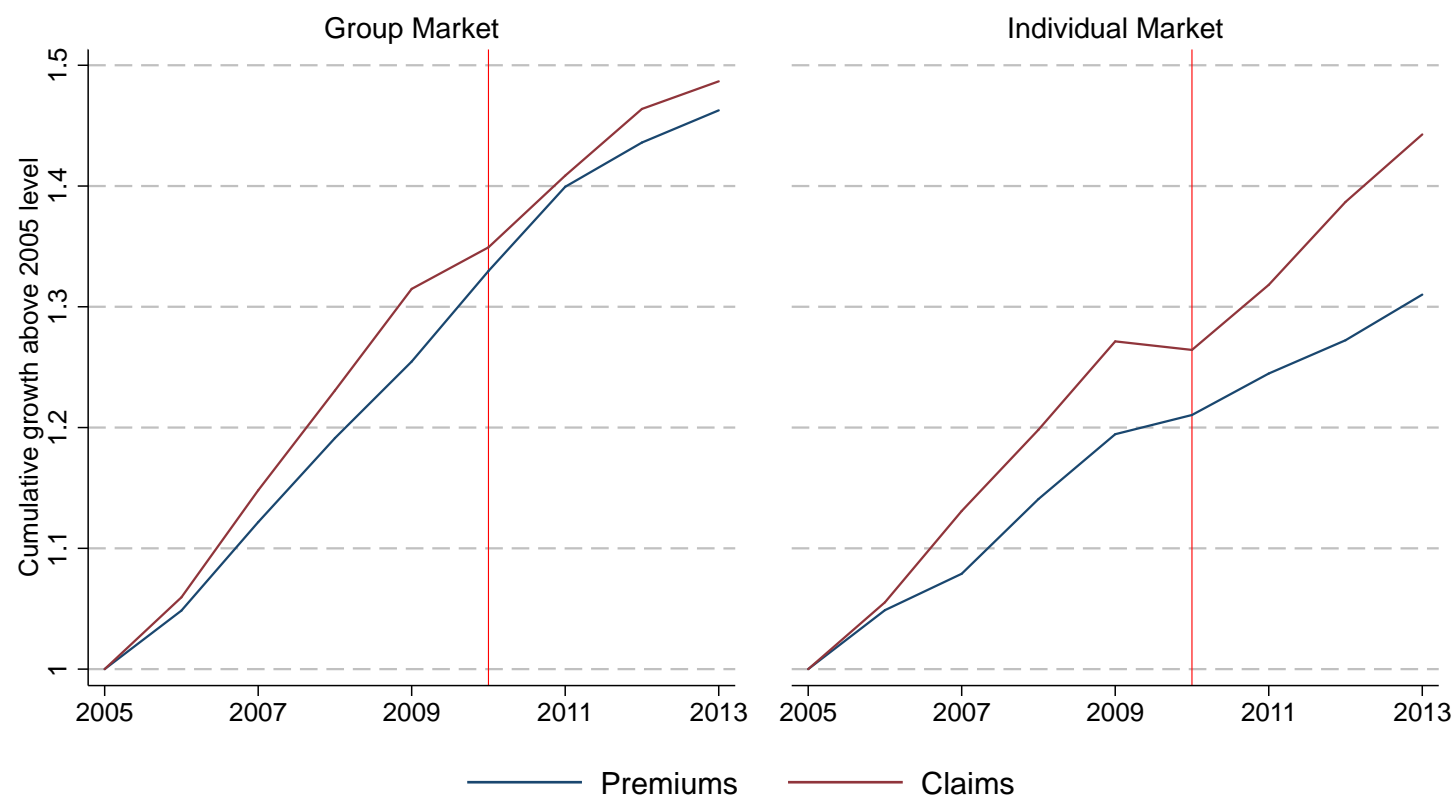

Note: The 2005 value of each series has been normalized to one. Growth is calculated on means that are enrollment weighted and taken from the panel of insurers used in our analysis from the NAIC data.

Next, Table 1 presents summary statistics for the analysis datasets in each market segment (group and individual) during the pre-period (2005-2010). It shows the average policyholder purchased a plan that was just in compliance with the eventual federal regulations. Premiums account for $4-6 \%$ of median income over this period ( $~ \$ 55,000 /$ year $)$. Claims and premiums tend to be higher in the group market than individual market. This is a highly concentrated industry, as is well-known, with even greater concentration in the market for individual insurance (an HHI of 10,000 represents perfect monopoly, and the Department of Justice defines concentrations in excess of 2,500 to be highly concentrated). We have found the utilization measures in the NAIC data ("Ambulatory encounters" and "Inpatient admissions") to be somewhat noisy (and do not use them elsewhere in our analysis), but the means broadly reflect the difference in claims between market segments. ${ }^{22}$

22 "Ambulatory encounters" are any broadly defined contacts with health providers on an outpatient basis. 
Table 1: Insurer Summary Statistics (2005-2010)

\begin{tabular}{lcc}
\hline & & \\
& Group Market & Individual Market \\
\hline MLR & 0.85 & 0.81 \\
& {$[0.06]$} & {$[0.13]$} \\
Claims PMPM & 242 & 169 \\
Premiums PMPM & {$[59]$} & {$[72]$} \\
& 284 & 208 \\
\# of insurers per state & {$[67]$} & {$[68]$} \\
& 12.4 & 4.3 \\
State market HHI & {$[6.2]$} & {$[2.9]$} \\
& 2,617 & 5,873 \\
Percent nonprofit & {$[1,795]$} & {$[2,594]$} \\
& 0.39 & 0.39 \\
Ambulatory encounters per life-year & {$[0.49]$} & {$[0.49]$} \\
& 9.6 & 7.8 \\
Inpatient admissions per life-year & {$[6.1]$} & {$[6.7]$} \\
Lives per insurer in 2010 (000s) & 0.07 & 0.05 \\
& {$[0.03]$} & {$[0.04]$} \\
Total lives in 2010 (000s) & 107.8 & 37.4 \\
\# of insurers in 2010 & {$[207.9]$} & $62.5]$ \\
\hline
\end{tabular}

Note: Insurer statistics are enrollment-weighted. Standard deviations are given in brackets.

\section{Empirical Strategy}

Estimating the causal impact of minimum MLR requirements on insurer behavior in this setting presents two main empirical challenges. First, the level of "treatment," meaning the difference between an insurer's unconstrained MLR and the regulated minimum, is unobserved. Second, treatment is not randomly assigned, but depends on equilibrium objects determined endogenously depending on demand, market structure, and regulation. In this section, we describe how features of the regulation permit the use of a difference-in-difference design to bound the causal impact under standard assumptions.

Minimum MLR regulation requires that firm $i$ in year $t$ refund its customers if its realized MLR, $m_{i t}$, is below some threshold $k .^{23}$ Nothing is required of the firm if its MLR is above $k$. However, $m_{i t}$ is an equilibrium outcome determined after annual claims cost and premium uncertainty is resolved, so the contemporaneous distance from $k$ cannot be used as a measure

\footnotetext{
${ }^{23}$ In practice, this exact threshold allows for adjustments based on the number of lives covered by the insurer and special exemptions. We assume a single threshold here for ease of exposition. In addition, the unit of observation $i$ is technically a firm-state-market combination.
} 
of the intensity of treatment. Instead, let $m_{i t}^{*}$ denote what the firm's profit maximizing target MLR would have been if not for the regulation. ${ }^{24}$ This suggests the kinked treatment design

$$
d_{i t}^{*}= \begin{cases}0 & \text { if } m_{i t}^{*} \geq k \\ \left(k-m_{i t}^{*}\right) & \text { if } m_{i t}^{*}<k\end{cases}
$$

Where $d_{i t}^{*}$ is firm $i$ 's true continuous level of treatment in year $t$. Although in reality firms are either "treated" or "untreated" on a yearly basis, our empirical strategy will rely only upon a firm's estimated treatment based on the mean of observed MLRs in the five years preceding the ACA, defined as $\hat{m}_{i}$, to measure the persistent component of a firm's distance from $k{ }^{25}$ Our continuous treatment measure $\hat{d}_{i}$ is defined analogously to the true treatment measure above, but uses these noisy estimates $\hat{m}_{i}$ instead of the true unobserved $m_{i t}^{*}$. This treatment definition is motivated by the fact that $70 \%$ (60\%) of the MLR variation in the individual (group) market during the baseline period is due to these time-invariant differences across insurers. Using the mean $m_{i t}$ from the five-year baseline period 2006-2010 also prevents an anomalously low MLR just before the ACA from categorizing a firm into treatment, and subsequent mean-reversion from producing spurious results.

Measurement error in the treatment variable introduces attenuation bias to our estimates of the impact of minimum MLR regulations. Attenuation takes two forms: first, on the extensive margin, firms are mis-categorized in and out of treatment depending on whether the error is larger or smaller than $k-m_{i t}^{*}$. Second, on the intensive margin the mis-measurement of treatment intensity induces classical measurement error.

Converting treatment into a binary measure depending on the sign of $k-\hat{m}_{i}$ limits measurement error to the extensive margin of mis-categorization. This is particularly helpful in the kinked design because firms most likely to be mis-categorized are those with the lowest levels of treatment. This substantially reduces the attenuation of treatment effect estimates relative to situations in which treatment is uniform once the running variable crosses the threshold. On the other hand, when much of the treated data is close to the threshold (as it is in our case), fitting a slope parameter allows the insurers predicted to be most treated (those with low $\hat{m}_{i t}$ ) to exert greater influence on the estimate of the effect. Ultimately, the binary treatment measures the average effect on the treated population (and will be small if most of the sample is lightly treated), while the kinked design estimates the effect of an additional MLR-point of distance below the minimum threshold. In Appendix Section B.3 we employ an instrumental variables strategy to reduce measurement error. We use noisy estimates from part of the pre-period to in-

\footnotetext{
${ }^{24}$ We emphasize that a firm's target MLR, $m_{i t}^{*}$, is based on decisions made at the beginning of the year (regarding, e.g., premiums and effort) as well as on expected claims costs. Realized claims costs will not be known until the end of the year.

${ }^{25}$ General robustness to the width of this window is shown in Appendix B.1.
} 
strument for noisy-estimates from the other part of the pre-period, finding qualitatively similar and statistically indistinguishable results, suggesting that measurement error has a relatively minor impact on our estimates. ${ }^{26}$

The second main empirical challenge is that MLRs are not randomly assigned: costs and premiums are choice variables, so that firms are treated according to endogenous business decisions. Using the time-invariant definition of treatment assignment described above ensures that transitory shocks are not pushing firms in to one group or another. Combining this treatment definition with a complete set of insurer $\left(\gamma_{i}\right)$ and year $\left(\delta_{t}\right)$ fixed effects yields a difference-indifference framework of the form

$$
y_{i t}=\gamma_{i}+\delta_{t}+\tau D_{i t}+\beta t \mathbb{1}\left\{\hat{d}_{i}>0\right\}+u_{i t}
$$

where $D_{i t} \equiv \mathbb{1}\left\{\hat{d}_{i}>0 ; t>2010\right\}$ in the binary treatment version (and $\mathbb{1}\{\cdot\}$ is an indicator function evaluating to one if the statement inside is true), or $D_{i t} \equiv \hat{d}_{i}$ for the continuous treatment version, and $y_{i t}$ is an outcome variable of interest. The parameter $\beta$ measures the slope of a treatment group-specific linear trend, which is omitted in the event-study figures that estimate year-specific $\tau_{t}$. This framework identifies the treatment effect based on the change in exposure to MLR regulation experienced between the pre- and post-period, recognizing that firms with $\hat{d}_{i}<0$ were already in compliance before the regulation took effect, and therefore serve as the control group. This requires that unobservable determinants of outcomes be either time-invariant, common across firms, or linear in time according to treatment group assignment. We use event-study-type figures to diagnose the potential for confounding differential trends, as well as demonstrate the robustness of our results to various specifications of unobservables.

The key remaining threat to identification is that other regulations also implemented as part of the ACA might have had a differential impact on firms depending on their baseline MLR. To diagnose the potential magnitude of this concern, we also evaluate enrollment as an outcome variable: regulations mandating coverage for particular groups (such as dependents up to age 26) should lead to a differential change in enrollment if it were to confound our estimates of the impact of minimum MLR regulations. On the other hand, signing up a disproportionate number of high-risk individuals might also be an insurer's strategy for MLR compliance. Thus this diagnostic rules out a potential threat if an effect is not detected, but does not necessarily invalidate the exercise if there is a relative change in enrollments coincident with the ACA. ${ }^{27}$

\footnotetext{
${ }^{26}$ It is unfortunately not possible to use states' heterogenous MLR regulation preceding the ACA as an instrumental variable for treatment since only eight firms experienced a state-based change in MLR regulation during the baseline period, making the instrument nearly completely collinear with firm fixed effects.

27 The wider roll-out of exchanges for individual coverage in 2014 substantially disrupts the individual market for health insurance, and thus as mentioned previously, we end our analysis in 2013.
} 
Table 2 presents summary statistics for firms separated by the binary measure of treatment $\left(D_{i} \equiv \mathbb{1}\left\{\hat{d}_{i}>0\right\}\right)$ during the baseline period, for both the group and individual market segments. Consistent with Table 1, it shows that the distance beneath the minimum threshold was substantially larger among treated firms in the individual market than the group market. In both market segments, the driver of lower MLRs among treated insurers is significantly lower claims costs than their untreated counterparts, with the gap in premiums between the two groups being much narrower. For example, in the individual segment, average premiums among untreated insurers were $11 \%$ higher than among treated insurers, while average claims were $37 \%$ higher. For differences in ambulatory encounters to explain the gap in claims between these groups, each additional encounter in the treatment group would have to cost $\$ 600(\$ 300)$ more than in the untreated group in the individual (group) market. Given that treated insurers are substantially larger than untreated insurers, it seems likely that treated insurers are able to negotiate lower prices with providers (?), and perhaps otherwise take advantage of economies of scale. The fact that the average treated insurer in both market segments had more policyholders than their untreated counterparts also suggests that a smaller customer base to cover fixed costs (thus requiring a higher operating margin) was not the reason for their persistently lower MLRs. Nonprofits were exempt from minimum MLR regulation, and so are never classified as treated, regardless of their MLR.

Finally, using our binary measure of treatment, we can present a graphical description of the data that is now broken out between treated and untreated insurers. Figures 5 and 6 recreate the same plots shown in Figure 4, but now separately for treated and untreated insurers for each market segment. As before, weighted average claims and premiums are expressed as growth rates above their 2005 levels. Starting with the individual market in Figure 5, it is immediately evident that there appears to be a break in trend in the growth of claims costs of treated insurers in 2011, with no such break experienced by untreated insurers or in the premium series of either set of insurers. In the group segment, shown in Figure 6, there is not as obvious of a movement in means between treated and untreated insurers, but it appears that claims and premiums for treated insurers grow more quickly that those of untreated insurers after 2011. In the next section, we aim to formalize and quantify the findings suggested in these figures using regression analysis. 
Table 2: Insurer Summary Statistics by Treatment (2005-2010)

\begin{tabular}{|c|c|c|c|c|}
\hline & \multicolumn{2}{|c|}{ Group Market } & \multicolumn{2}{|c|}{ Individual Market } \\
\hline & Treated & Untreated & Treated & Untreated \\
\hline \multirow[t]{2}{*}{ MLR } & 0.80 & 0.87 & 0.71 & 0.87 \\
\hline & {$[0.04]$} & {$[0.05]$} & {$[0.07]$} & {$[0.12]$} \\
\hline \multirow{2}{*}{ Claims PMPM } & 223 & 248 & 137 & 188 \\
\hline & {$[50]$} & {$[61]$} & {$[29]$} & {$[83]$} \\
\hline \multirow[t]{2}{*}{ Premiums PMPM } & 281 & 286 & 194 & 216 \\
\hline & {$[60]$} & {$[70]$} & {$[35]$} & {$[80]$} \\
\hline \multirow[t]{2}{*}{ \# of insurers per state } & 3.1 & 10.5 & 2.3 & 3.8 \\
\hline & {$[1.5]$} & {$[5.6]$} & {$[1.5]$} & {$[3.0]$} \\
\hline \multirow{2}{*}{ State market HHI } & 2,550 & 2,642 & 6,218 & 5,667 \\
\hline & {$[1,419]$} & {$[1,916]$} & {$[2,377]$} & {$[2,697]$} \\
\hline \multirow{2}{*}{ Percent nonprofit } & 0.00 & 0.53 & 0.00 & 0.62 \\
\hline & {$[0.00]$} & {$[0.50]$} & {$[0.00]$} & {$[0.49]$} \\
\hline \multirow[t]{2}{*}{ Ambulatory encounters per life-year } & 8.9 & 9.9 & 6.0 & 8.9 \\
\hline & {$[5.7]$} & [ 6.2] & {$[4.1]$} & {$[7.7]$} \\
\hline \multirow{2}{*}{ Inpatient admissions per life-year } & 0.07 & 0.07 & 0.05 & 0.05 \\
\hline & {$[0.03]$} & {$[0.03]$} & {$[0.06]$} & {$[0.03]$} \\
\hline \multirow[t]{2}{*}{ Lives per insurer in 2010 (000s) } & 127.6 & 101.7 & 49.2 & 32.3 \\
\hline & {$[192.0]$} & [212.5] & {$[87.6]$} & {$[47.4]$} \\
\hline Total lives in 2010 (000s) & 11,990 & 30,606 & 2,655 & 4,036 \\
\hline \# of insurers in 2010 & 94 & 301 & 54 & 125 \\
\hline
\end{tabular}

Note: Statistics are enrollment-weighted. Standard deviations are given in brackets. 
Figure 5: Cumulative Growth of Claims and Premiums in the Individual Market, by Treatment
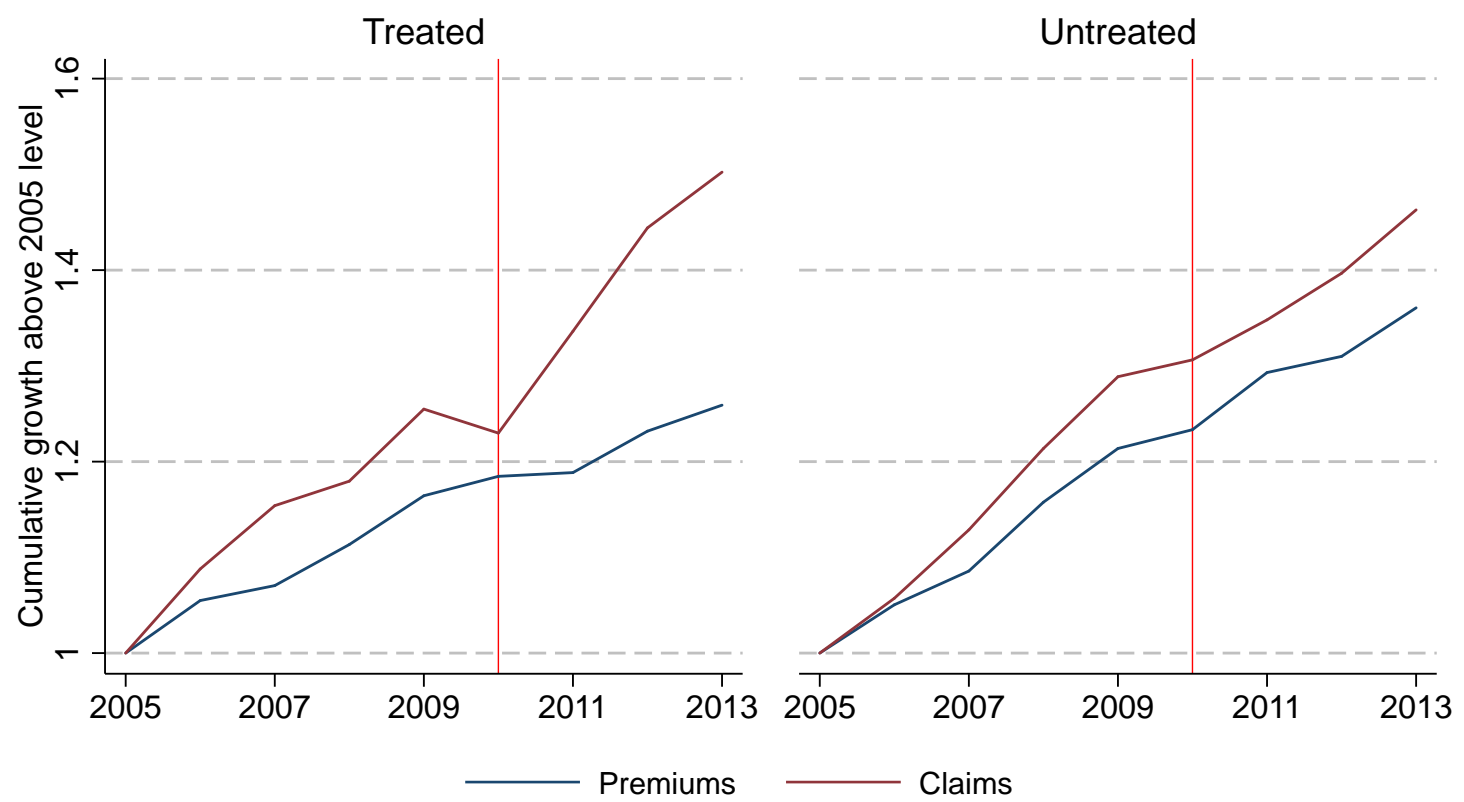

Note: The 2005 value of each series has been normalized to one. Growth is calculated on means that are enrollment weighted and taken from the panel of insurers used in our analysis from the NAIC data. Treatment $\equiv D_{i} \equiv \mathbb{1}\left\{\hat{d}_{i}>0\right\}$.

Figure 6: Cumulative Growth of Claims and Premiums in the Group Market, by Treatment

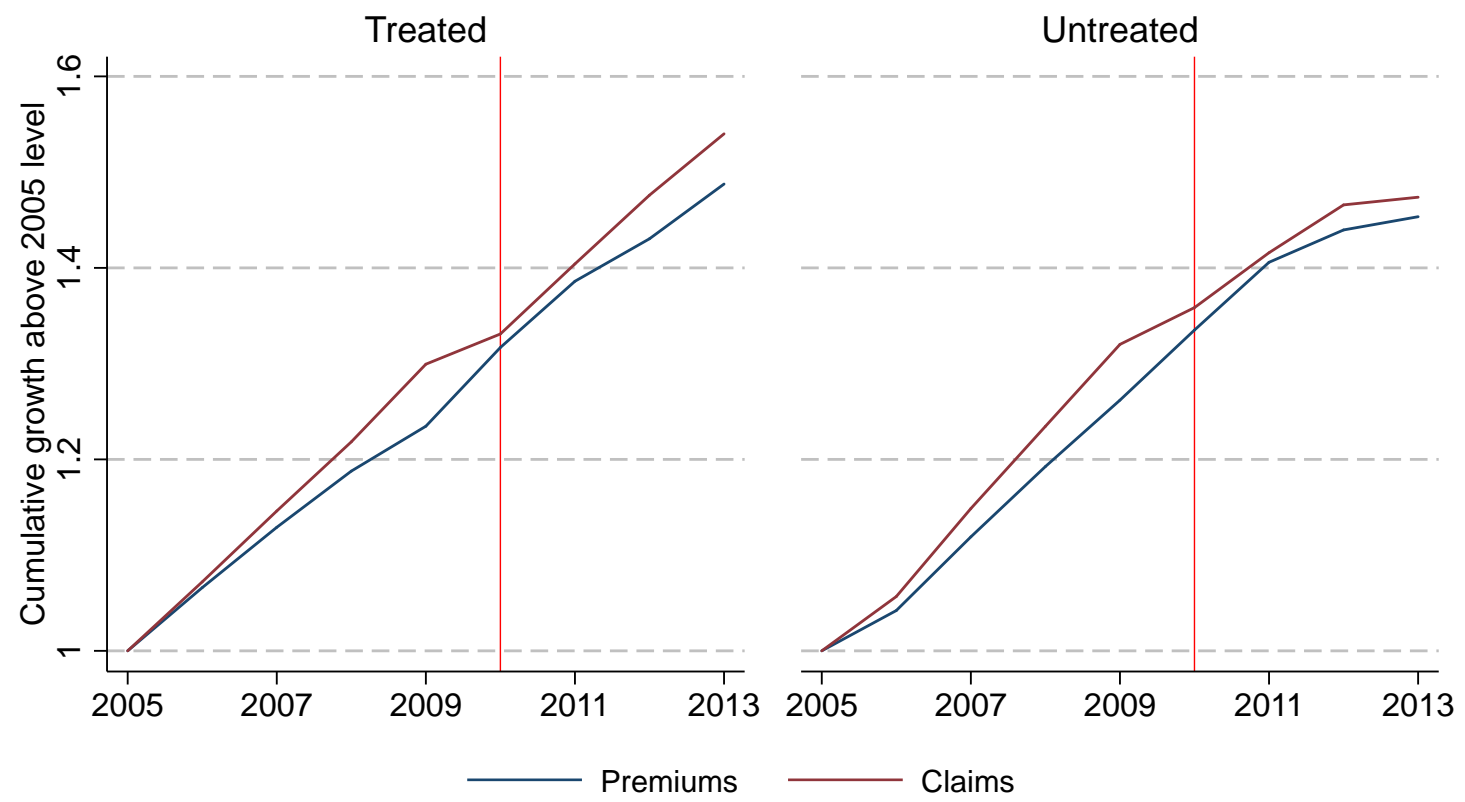

Note: The 2005 value of each series has been normalized to one. Growth is calculated on means that are enrollment weighted and taken from the panel of insurers used in our analysis from the NAIC data. Treatment $\equiv D_{i} \equiv \mathbb{1}\left\{\hat{d}_{i}>0\right\}$. 


\section{Results}

In this section, we begin by presenting event-study plots of our main empirical specifications, which serve to provide a graphic illustration of our findings as well as motivate our final regression specification. We then present our main results using the outcome variables of $M L R$, $\ln$ (Claims), and $\ln$ (Premiums), using both our binary and continuous definitions of treatment, in both the individual and group market segments. We also present the results using various alternative specifications, confirming the robustness of our results. We then use enrollment as the outcome variable to bound the extent to which differential changes might explain our results. Finally, we use Quality Improvement expenditures and administrative costs as outcome variables to provide suggestive evidence of how insurers may have complied with MLR regulation.

\section{Estimates by Year to Implementation}

Figure 7 presents regression-adjusted estimates of the difference in average MLRs across the treated and control groups for each year, relative to 2010. It is based on our empirical specification in equation (6), but estimates each $\tau_{t}$ separately and does not control for a differential treatment group-specific trend. By omitting this variable, we are able to assess the extent to which a difference in trends across our treated and control groups might contribute to the overall point estimate. As seen in Panel (a), in the individual market, the treated and control groups have similar MLRs between 2005 and 2010. However, as soon as the rule is implemented, MLRs rise in the treated group relative to those in the control group. Panel (b) shows similar findings in the group market, though the magnitude of the increase is smaller, consistent with the distributions of pre-period MLRs presented in Section II.

Next, Figure 8 shows analogous results using the natural $\log$ of claims per life-year as the outcome variable. Panel (a) presents the individual market, where claims for treated firms appear to be falling slightly relative to untreated firms. This further motivates the separate trend for the treated group in our main specifications. Upon the implementation of the ACA's MLR regulation in 2011, the treated group's claims jump up and continue to rise. Panel (b) shows the results in the group market, where the treated and control firms have similar claims costs prior to the ACA. After MLR regulation goes into effect, claims in the treated group appear to grow slightly relative to those in the control group. However, the estimates are imprecise and there appears to be a role for differential trends to play in lowering the ultimate point estimate.

Figure 9 presents the same analysis using the natural log of premiums per life-year as the outcome variable. Again, Panel (a) shows the individual market, and reveals a downward trend 
Figure 7: Treatment Effects by Year: $M L R$

(a) Individual Market

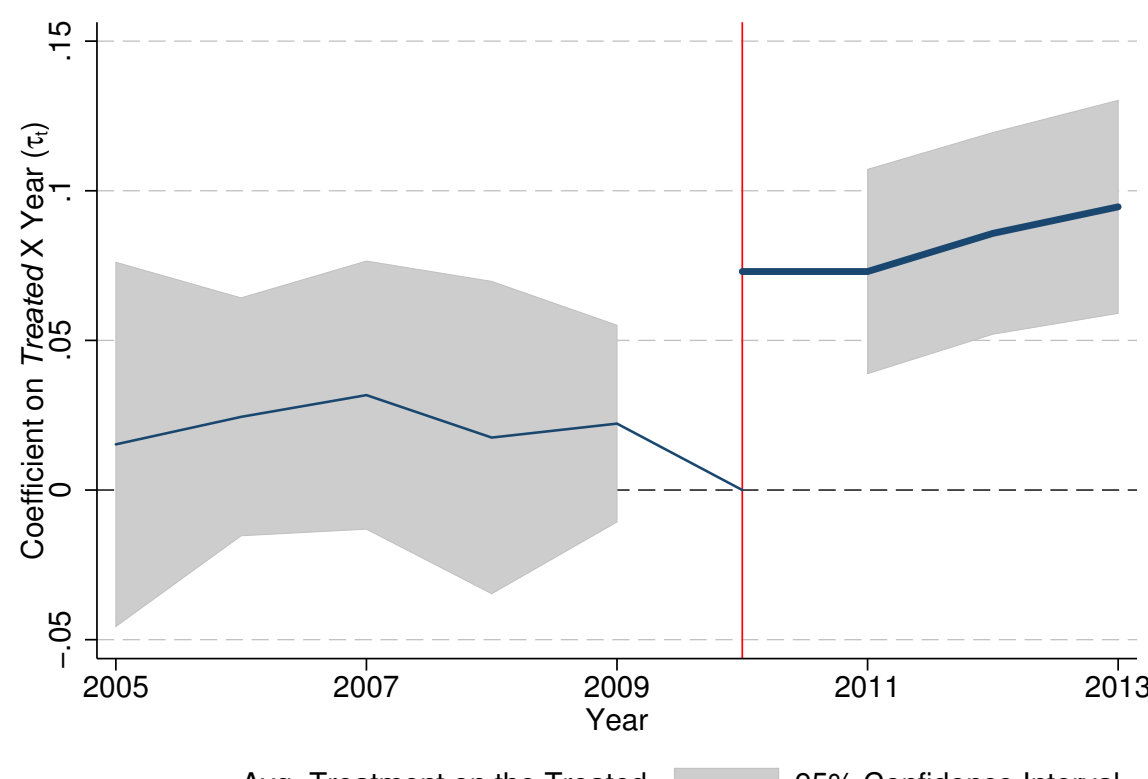

Avg. Treatment on the Treated

95\% Confidence Interval

(b) Group Market

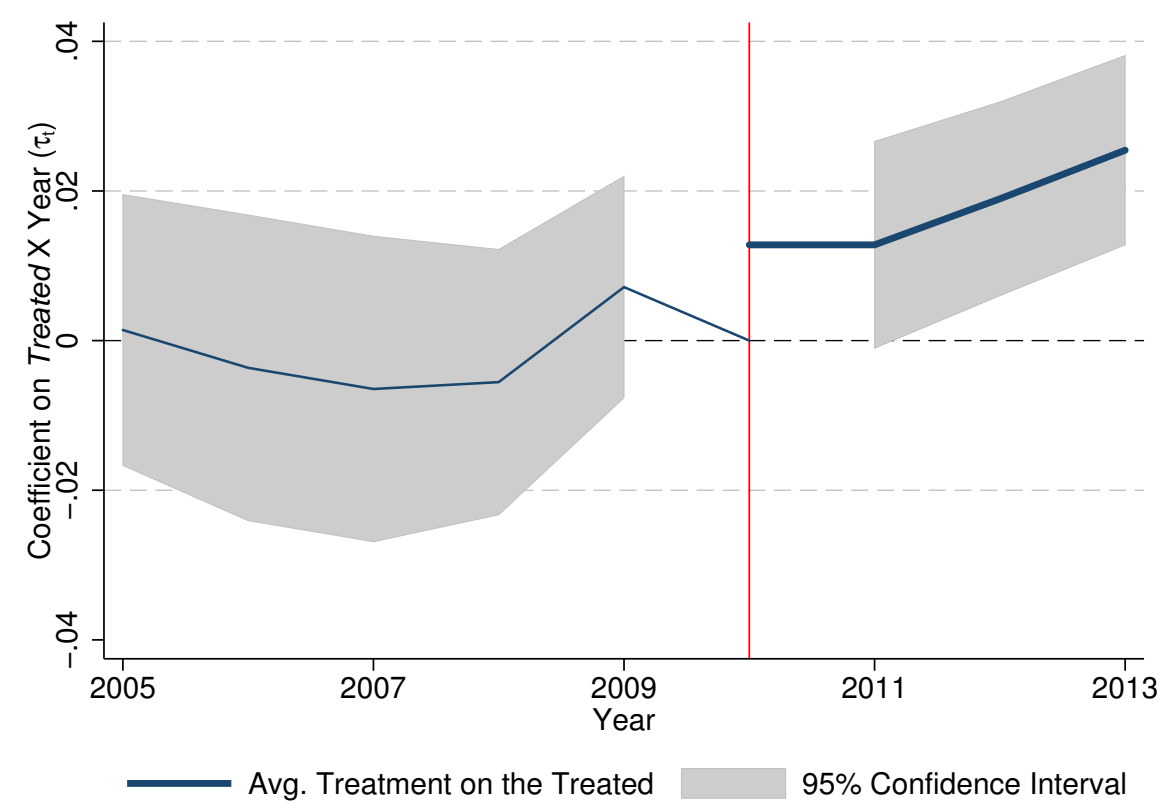

Note: Event-study figures are based on estimation of equation (6) using the binary definition of treatment, with year-specific treatment effects relative to 2010, and omitting the treatment group-specific linear trend. Regressions are weighted by enrollment, and standard errors are clustered by insurer. Treatment $\equiv \mathbb{1}\left\{\hat{d}_{i}>0\right\}$. 
Figure 8: Treatment Effects by Year: $\ln ($ Claims $)$

(a) Individual Market

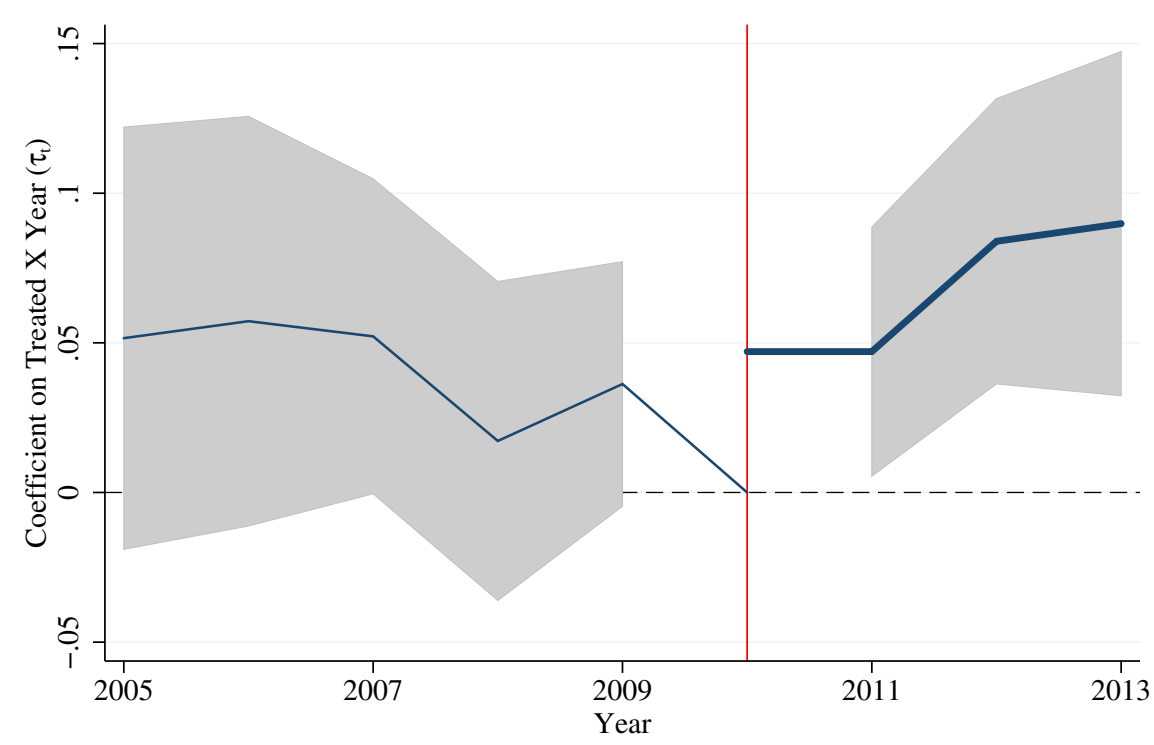

Avg. Treatment on the Treated $\quad 95 \%$ Confidence Interval

(b) Group Market

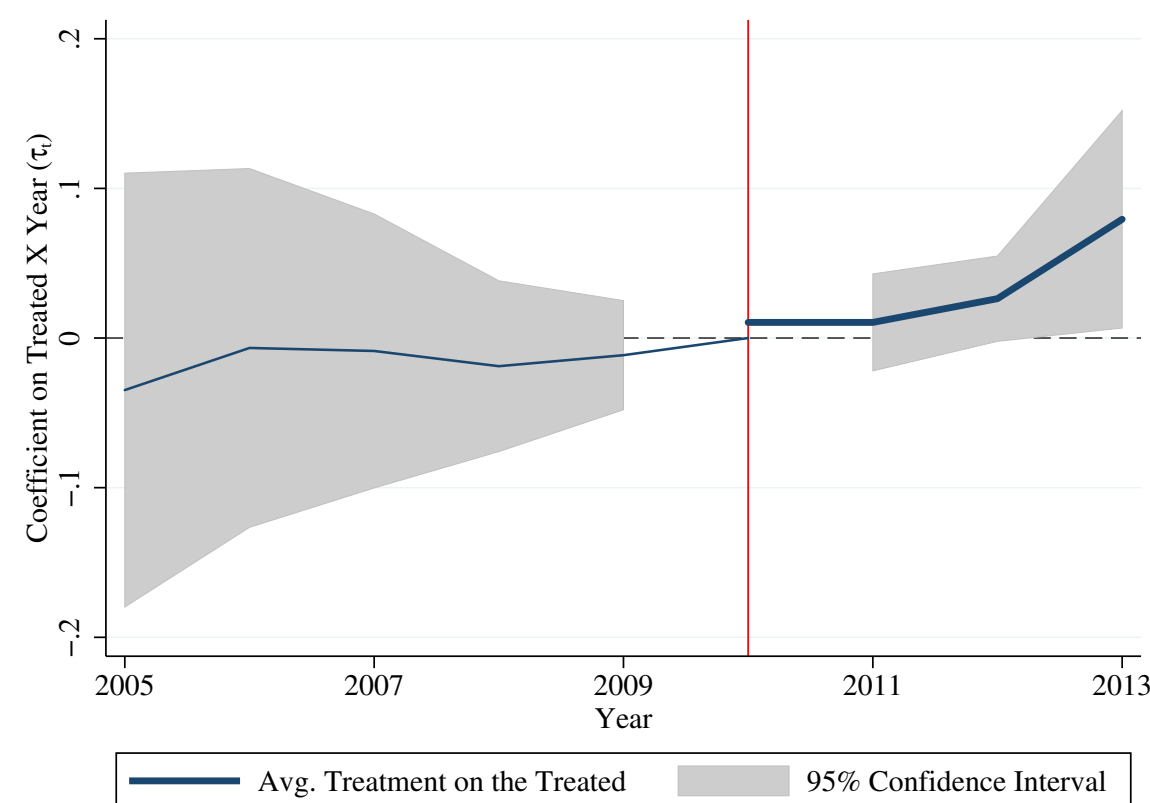

Note: Event-study figures are based on estimation of equation (6) using the binary definition of treatment, with year-specific treatment effects relative to 2010, and omitting the treatment group-specific linear trend. Regressions are weighted by enrollment, and standard errors are clustered by insurer. Treatment $\equiv \mathbb{1}\left\{\hat{d}_{i}>0\right\}$. The logged outcome variable Claims is measured on a per life-year basis. 
during the pre-period. In this case, it is not clear whether the lower premiums observed after 2011 are actually a response to the regulation, or simply the continuation of a previous trend. In the group market, Panel (b) shows a pattern quite similar to those of claims in Figure 8(b). Taken together, these figures suggest that MLRs increased after the passing of the ACA and that this increase is due largely to a rise in claims costs rather than a reduction in premiums. In addition, the differential pre-trends observed in claims costs and premiums motivate the inclusion of treatment group-specific linear trends in our main empirical specification, equation (6). Trends in claims costs and premium revenues were moving together in each market as to largely remove a differential trend in the MLR. 
Figure 9: Treatment Effects by Year: $\ln ($ Premiums $)$

(a) Individual Market

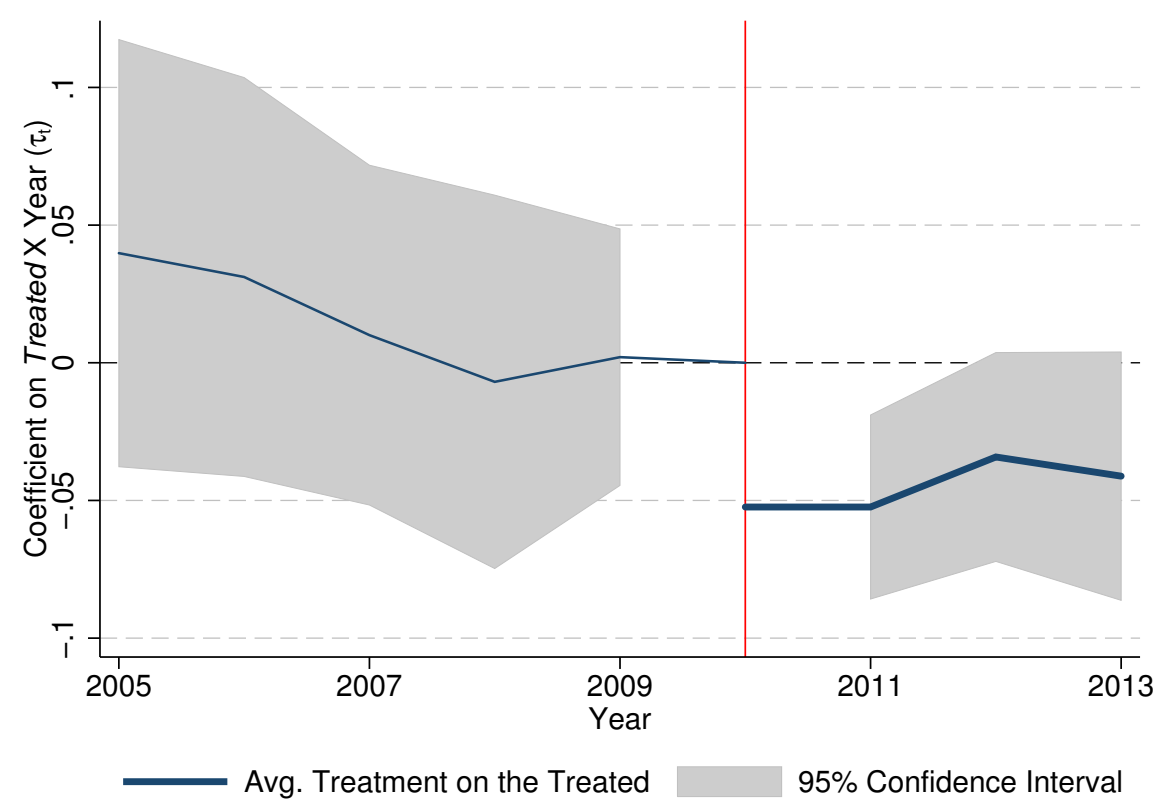

(b) Group Market

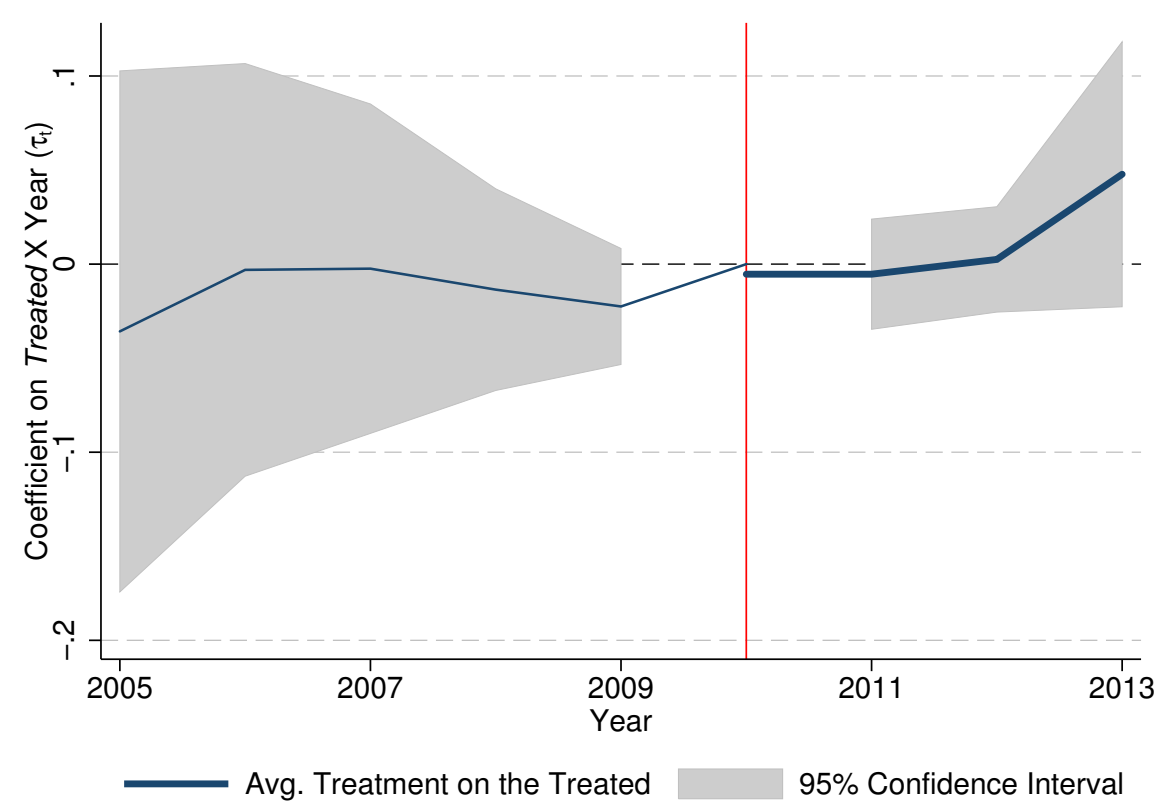

Note: Event-study figures are based on estimation of equation (6) using the binary definition of treatment, with year-specific treatment effects relative to 2010, and omitting the treatment group-specific linear trend. Regressions are weighted by enrollment, and standard errors are clustered by insurer. Treatment $\equiv \mathbb{1}\left\{\hat{d}_{i}>0\right\}$. The logged outcome variable Premiums is measured on a per life-year basis. 


\section{Main Specifications}

We now move to estimation of our main specifications, which we will present for both the individual and group market segments, as well as using both our binary and continuous definition of treatment. First, Table 3 reports the results of estimating equation (6) in the individual market with our binary treatment specification. We present results for three outcome variables: $M L R, \ln \left(\right.$ Claims), and $\ln$ (Premiums) ${ }^{28}$ If interpreted causally, the coefficients on Post-2011* Treatment indicate the average treatment effect of MLR regulation on the treated insurers. The coefficients on [Year] * Treatment for 2011, 2012, and 2013 show how the estimated treatment effect varied over the post-ACA period.

Table 3: Regression Results: Individual Market, Binary Treatment

\begin{tabular}{|c|c|c|c|c|c|c|}
\hline & \multicolumn{2}{|c|}{ MLR } & \multicolumn{2}{|c|}{$\ln$ (Claims) } & \multicolumn{2}{|c|}{$\ln$ (Premiums) } \\
\hline & (1) & $(2)$ & (3) & (4) & (5) & (6) \\
\hline Post-2011 * Treatment & $\begin{array}{c}0.073 \\
(0.018)^{* * *}\end{array}$ & & $\begin{array}{c}0.068 \\
(0.030)^{* *}\end{array}$ & & $\begin{array}{l}-0.025 \\
(0.024)\end{array}$ & \\
\hline $2011 *$ Treatment & & $\begin{array}{c}0.066 \\
(0.017)^{* * *}\end{array}$ & & $\begin{array}{c}0.048 \\
(0.027)^{*}\end{array}$ & & $\begin{array}{l}-0.036 \\
(0.022)\end{array}$ \\
\hline $2012 *$ Treatment & & $\begin{array}{c}0.082 \\
(0.020)^{* * *}\end{array}$ & & $\begin{array}{c}0.095 \\
(0.035)^{* * *}\end{array}$ & & $\begin{array}{l}-0.010 \\
(0.027)\end{array}$ \\
\hline $2013 *$ Treatment & & $\begin{array}{c}0.094 \\
(0.025)^{* * *}\end{array}$ & & $\begin{array}{c}0.112 \\
(0.042)^{* * *}\end{array}$ & & $\begin{array}{l}-0.008 \\
(0.035)\end{array}$ \\
\hline$R^{2}$ & 0.75 & 0.75 & 0.89 & 0.89 & 0.86 & 0.86 \\
\hline \# Insurers & 184 & 184 & 184 & 184 & 184 & 184 \\
\hline Observations & 1,417 & 1,417 & 1,417 & 1,417 & 1,417 & 1,417 \\
\hline
\end{tabular}

Note: Regressions are weighted by enrollment, and standard errors are clustered by insurer. All specifications include year fixed effects, insurer fixed effects, and a treatment group linear time trend. The outcome variables Claims and Premiums are measured on a per life-year basis. Treatment $\equiv \mathbb{1}\left\{\hat{d}_{i}>0\right\} .{ }^{*} \mathrm{p}<0.10,{ }^{* *} \mathrm{p}<0.05$, $* * * \mathrm{p}<.01$.

Our estimates suggest that treated insurers experienced an increase in MLR post-2011 that was 7.3 percentage points higher than the counterfactual, an amount roughly equal to treated insurers' average distance below the regulatory threshold (about 8\%). Column (2) confirms patterns in Figure 7: treated insurers experienced an immediate jump in MLRs in 2011 and small additional increases in each subsequent year. Moving to column (3), the claims costs of treated insurers rose by an average of $6.8 \%$ in the three years after the implementation of federal MLR regulation, above what their past trends and the experience of untreated firms would predict. Treated firms in the individual market appear to have adjusted their claims costs

\footnotetext{
${ }^{28}$ We note again here that Claims and Premiums are measured on a per life-year basis.
} 
somewhat gradually. Column (4) shows that the impact on treated insurers' claims increased as time passed, rising from a $4.8 \%$ increase in the first year of the regulation to more than $11 \%$ by 2013. In column (5), our point estimate suggests that premiums might have fallen slightly for treated insurers after the regulation went into effect, but we lack the statistical precision to reject the null of no effect. That said, the time path of the effect on premiums shown in column (6) is consistent with a small reduction in the first year of the regulation, but then subsequent adjustments with the effect that there was no impact on premiums three years out.

Next, Table 4 presents the results of the same analysis, but using our continuous definition of treatment, namely the distance below the MLR threshold a treated insurer was predicted to be in 2011. Here, a coefficient of one would imply that moving an insurer's target MLR one percentage point farther below the regulated threshold in 2011 would increase the corresponding outcome by $1 \%$, a sort of MLR distance-elasticity. Using this specification, we can see that, as expected, the treatment effect is strongly increasing in insurers' exposure to the regulation. In other words, insurers further below the regulatory threshold experience larger responses in both MLR and claims costs. In terms of magnitudes, the point estimates in columns (1) and (2) suggest that increasing treatment intensity by one MLR point (e.g., going from 0.07 to 0.08 below the MLR threshold) increases a firm's MLR in the post period by almost 0.007 (e.g., the rise in MLR goes from 0.049 to 0.056). Column (3) shows that the effect on claims is nearly identical and growing over time.

Table 4: Regression Results: Individual Market, Continuous Treatment

\begin{tabular}{|c|c|c|c|c|c|c|}
\hline & \multicolumn{2}{|c|}{ MLR } & \multicolumn{2}{|c|}{$\ln$ (Claims) } & \multicolumn{2}{|c|}{$\ln$ (Premiums) } \\
\hline & (1) & $(2)$ & (3) & (4) & $(5)$ & (6) \\
\hline Post-2011 * Treatment & $\begin{array}{c}0.695 \\
(0.117)^{* * *}\end{array}$ & & $\begin{array}{c}0.700 \\
(0.199)^{* * *}\end{array}$ & & $\begin{array}{c}-0.311 \\
(0.148)^{* *}\end{array}$ & \\
\hline $2011 *$ Treatment & & $\begin{array}{c}0.597 \\
(0.120)^{* * *}\end{array}$ & & $\begin{array}{c}0.415 \\
(0.184)^{* *}\end{array}$ & & $\begin{array}{c}-0.450 \\
(0.143)^{* * *}\end{array}$ \\
\hline $2012 *$ Treatment & & $\begin{array}{c}0.719 \\
(0.112)^{* * *}\end{array}$ & & $\begin{array}{c}0.836 \\
(0.210)^{* * *}\end{array}$ & & $\begin{array}{l}-0.214 \\
(0.162)\end{array}$ \\
\hline $2013 *$ Treatment & & $\begin{array}{c}0.835 \\
(0.162)^{* * *}\end{array}$ & & $\begin{array}{c}1.013 \\
(0.263)^{* * *}\end{array}$ & & $\begin{array}{l}-0.200 \\
(0.187)\end{array}$ \\
\hline$R^{2}$ & 0.75 & 0.76 & 0.89 & 0.89 & 0.86 & 0.86 \\
\hline \# Insurers & 184 & 184 & 184 & 184 & 184 & 184 \\
\hline Observations & 1,417 & 1,417 & 1,417 & 1,417 & 1,417 & 1,417 \\
\hline
\end{tabular}

Note: Regressions are weighted by enrollment, and standard errors are clustered by insurer. All specifications include year fixed effects, insurer fixed effects, and a treatment group linear time trend. The outcome variables Claims and Premiums are measured on a per life-year basis. Treatment $\equiv \hat{d}_{i}{ }^{*} \mathrm{p}<0.10,{ }^{* *} \mathrm{p}<0.05,{ }^{* * *}$ $\mathrm{p}<.01$. 
This specification again finds that treated insurers responded in the short run by lowering premiums, but that this effect diminished over time. Unlike the binary treatment specification, we now have the statistical power to reject the null of no effect on premiums in the first year following the implementation of MLR regulation. If there are greater adjustment costs to raising claims costs as opposed to simply dropping premiums, firms might choose to lower premiums in the short run, but in the longer run, might reoptimize over inputs (e.g., effort) such that claims ultimately rise and premiums return to whatever levels the market will bear.

Next, Table 5 and Table 6 present an equivalent analysis for the group market. Generally, the results closely parallel those we found for the individual market: MLRs and claims costs grew each year after the new regulation went into effect. Our coefficient estimates in the group market are closer to zero, reflecting the fact that the group market as a whole was much closer to compliance than the individual market. However, instead of finding reductions in premiums in the first year which then dissipated over time, our point estimates suggest that premiums might have risen in the group market during the post period. The relatively low treatment intensity received by insurers in the group market makes it difficult to distinguish the cost/premium components of change as statistically different from zero.

Table 5: Regression Results: Group Market, Binary Treatment

\begin{tabular}{|c|c|c|c|c|c|c|}
\hline & \multicolumn{2}{|c|}{ MLR } & \multicolumn{2}{|c|}{$\ln$ (Claims) } & \multicolumn{2}{|c|}{$\ln$ (Premiums) } \\
\hline & $(1)$ & $(2)$ & (3) & (4) & (5) & (6) \\
\hline Post-2011 * Treatment & $\begin{array}{c}0.015 \\
(0.007)^{* *}\end{array}$ & & $\begin{array}{c}0.019 \\
(0.024)\end{array}$ & & $\begin{array}{c}0.003 \\
(0.022)\end{array}$ & \\
\hline $2011 *$ Treatment & & $\begin{array}{c}0.011 \\
(0.007)\end{array}$ & & $\begin{array}{c}0.009 \\
(0.019)\end{array}$ & & $\begin{array}{l}-0.004 \\
(0.016)\end{array}$ \\
\hline $2012 *$ Treatment & & $\begin{array}{c}0.017 \\
(0.009)^{*}\end{array}$ & & $\begin{array}{c}0.020 \\
(0.029)\end{array}$ & & $\begin{array}{c}0.001 \\
(0.025)\end{array}$ \\
\hline $2013 *$ Treatment & & $\begin{array}{c}0.023 \\
(0.009)^{* *}\end{array}$ & & $\begin{array}{c}0.069 \\
(0.060)\end{array}$ & & $\begin{array}{c}0.043 \\
(0.057)\end{array}$ \\
\hline$R^{2}$ & 0.69 & 0.69 & 0.86 & 0.86 & 0.87 & 0.87 \\
\hline \# Insurers & 406 & 406 & 406 & 406 & 406 & 406 \\
\hline Observations & 3,295 & 3,295 & 3,295 & 3,295 & 3,295 & 3,295 \\
\hline
\end{tabular}

Note: Regressions are weighted by enrollment, and standard errors are clustered by insurer. All specifications include year fixed effects, insurer fixed effects, and a treatment group linear time trend. The outcome variables Claims and Premiums are measured on a per life-year basis. Treatment $\equiv \mathbb{1}\left\{\hat{d}_{i}>0\right\} .{ }^{*} \mathrm{p}<0.10,{ }^{* *} \mathrm{p}<0.05$, $* * * \mathrm{p}<.01$. 
Table 6: Regression Results: Group Market, Continuous Treatment

\begin{tabular}{|c|c|c|c|c|c|c|}
\hline & \multicolumn{2}{|c|}{ MLR } & \multicolumn{2}{|c|}{$\ln ($ Claims $)$} & \multicolumn{2}{|c|}{$\ln$ (Premiums) } \\
\hline & (1) & $(2)$ & (3) & (4) & $(5)$ & (6) \\
\hline Post-2011 * Treatment & $\begin{array}{c}0.523 \\
(0.123)^{* * *}\end{array}$ & & $\begin{array}{c}1.255 \\
(0.651)^{*}\end{array}$ & & $\begin{array}{c}0.577 \\
(0.654)\end{array}$ & \\
\hline $2011 *$ Treatment & & $\begin{array}{c}0.464 \\
(0.117)^{* * *}\end{array}$ & & $\begin{array}{c}0.930 \\
(0.695)\end{array}$ & & $\begin{array}{c}0.333 \\
(0.712)\end{array}$ \\
\hline $2012 *$ Treatment & & $\begin{array}{c}0.502 \\
(0.142)^{* * *}\end{array}$ & & $\begin{array}{c}1.104 \\
(0.631)^{*}\end{array}$ & & $\begin{array}{c}0.446 \\
(0.623)\end{array}$ \\
\hline $2013 *$ Treatment & & $\begin{array}{c}0.634 \\
(0.146)^{* * *}\end{array}$ & & $\begin{array}{c}1.917 \\
(0.827)^{* *}\end{array}$ & & $\begin{array}{c}1.095 \\
(0.808)\end{array}$ \\
\hline$R^{2}$ & 0.70 & 0.70 & 0.86 & 0.87 & 0.87 & 0.87 \\
\hline \# Insurers & 406 & 406 & 406 & 406 & 406 & 406 \\
\hline Observations & 3,295 & 3,295 & 3,295 & 3,295 & 3,295 & 3,295 \\
\hline
\end{tabular}

Note: Regressions are weighted by enrollment, and standard errors are clustered by insurer. All specifications include year fixed effects, insurer fixed effects, and a treatment group linear time trend. The outcome variables Claims and Premiums are measured on a per life-year basis. Treatment $\equiv \hat{d}_{i}{ }^{*} \mathrm{p}<0.10,{ }^{* *} \mathrm{p}<0.05,{ }^{* * *}$ $\mathrm{p}<.01$.

\section{Robustness to Alternative Specifications}

Changes in market structure, such as increased consolidation of providers or the entry of new health insurers, potentially seem likelier to occur in markets where health insurers have market power. Since Karaca-Mandic et al. (2015) have found that low MLRs are associated with market power, we might think these other changes are happening more frequently in states and years in which there is a higher concentration of low MLR insurers. To rule out these stories, and others that would create confounding variation at the state-by-year level (such as the early Medicaid expansions), we also include state-by-year fixed effects into our specifications. Table 7 presents these results for the individual market, binary treatment specification, with MLR as the outcome of interest. The first two columns reproduce our baseline results, and columns (3) and (4) show the results once state-by-year fixed effects have been included. The results are qualitatively similar (if not somewhat stronger), and statistically indistinguishable.

Table 7 also shows the results once we have dropped nonprofit insurers. Nonprofit insurers were required to report their financial information just as for-profit insurers were, but they were not actually subject to the same MLR requirements. It was not until 2014 when nonprofit insurers faced any penalties for not meeting the federal MLR thresholds. ${ }^{29} \mathrm{Up}$ to this point in the analysis, we have treated nonprofits as firms that were in compliance with their MLR requirements, regardless of their actual MLRs. However, unlike the hospital market where for-profit

${ }^{29}$ Nonprofit insurers were faced with losing the tax advantages they gain through their nonprofit status (Kirchhoff, 2014). 
Table 7: Sensitivity Results: Individual Market, Binary Treatment

\begin{tabular}{|c|c|c|c|c|c|c|}
\hline & \multicolumn{6}{|c|}{ MLR } \\
\hline & (1) & $(2)$ & $(3)$ & (4) & $(5)$ & (6) \\
\hline Post-2011 * Treatment & $\begin{array}{c}0.073 \\
(0.018)^{* * *}\end{array}$ & & $\begin{array}{c}0.081 \\
(0.024)^{* * *}\end{array}$ & & $\begin{array}{c}0.077 \\
(0.022)^{* * *}\end{array}$ & \\
\hline $2011 *$ Treatment & & $\begin{array}{c}0.066 \\
(0.017)^{* * *}\end{array}$ & & $\begin{array}{c}0.074 \\
(0.024)^{* * *}\end{array}$ & & $\begin{array}{c}0.067 \\
(0.021)^{* * *}\end{array}$ \\
\hline $2012 *$ Treatment & & $\begin{array}{c}0.082 \\
(0.020)^{* * *}\end{array}$ & & $\begin{array}{c}0.113 \\
(0.032)^{* * *}\end{array}$ & & $\begin{array}{c}0.089 \\
(0.025)^{* * *}\end{array}$ \\
\hline $2013 *$ Treatment & & $\begin{array}{c}0.094 \\
(0.025)^{* * *}\end{array}$ & & $\begin{array}{c}0.149 \\
(0.042)^{* * *}\end{array}$ & & $\begin{array}{c}0.109 \\
(0.030)^{* * *}\end{array}$ \\
\hline State-by-year f.e. & No & No & Yes & Yes & No & No \\
\hline Exclude nonprofits & No & No & No & No & Yes & Yes \\
\hline$R^{2}$ & 0.75 & 0.75 & 0.85 & 0.85 & 0.71 & 0.71 \\
\hline \# Insurers & 183 & 183 & 183 & 183 & 125 & 125 \\
\hline Observations & 1,412 & 1,412 & 1,412 & 1,412 & 926 & 926 \\
\hline
\end{tabular}

Note: The dependent variable in all columns is MLR. Columns (1) and (2) reproduce results from our main specification. Columns (3) and (4) include state-by-year fixed effects. Columns (5) and (6) drop insurers that were ever nonprofits. Regressions are weighted by enrollment, and standard errors are clustered by insurer. All specifications include insurer fixed effects and a treatment group linear time trend. Treatment $\equiv \mathbb{1}\left\{\hat{d}_{i}>0\right\} .{ }^{*}$ $\mathrm{p}<0.10,{ }^{* *} \mathrm{p}<0.05,{ }^{* * *} \mathrm{p}<.01$.

and nonprofit hospitals behave very similarly (Norton and Staiger, 1994; Sloan, 2000; Picone et al., 2002), for-profit and nonprofit insurers do not appear to do so (Dafny and Ramanarayanan, 2012; Lieber, 2017). Because of this, it is not clear that nonprofit insurers can be reasonably included in our control group. Despite these potential differences, columns (5) and (6) show that nonprofit insurers are not driving our results, as our point estimates are largely unaffected when we drop nonprofit insurers altogether. We have conducted these same alternative analyses for our continuous treatment measure in the individual market, as well as for both treatment measures in the group market. In each case, the state-by-year fixed effects and the exclusion of nonprofits from our sample has no material impact on our estimates. Tables with these results are included in Appendix B.1.

To address directly whether our results can be explained by variation in market power or market concentration, we next present specifications in which we interact our main treatment variables with such measures. Table 8 presents our main specifications using the binary treatment definition in the individual market, but adding interactions with either insurer market share or state HHI. The results are presented for our three main outcome variables: MLR, claims, and premiums. The variable MktShare is constructed at the insurer-state level, and gives each insurer's market share in the individual segment. The variable $H H I$ is constructed at the state level, and measures the concentration of the individual health insurance market in that state. Both measures are based on 2010 data. We do not find strong evidence that 
the magnitude of treatment effects are correlated with either insurer market share nor market structure. However, given that these variables are strongly correlated with whether an insurer was treated in the first place (see Table 2), the presence of these controls reduces the precision of our treatment effect estimates. The HHI interactions suggest that more competitive markets are more likely to achieve MLR increases with a balanced combination of premium reductions and claims increases, while concentrated areas focus on increasing claims (complementary to the findings of (Cabral et al., 2015)), but we lack statistical precision to reject identical responses. The corresponding results for our continuous treatment measure and the group segment are presented in Appendix B.4. We find similar results for the individual market using the continuous measure of treatment, and suggestive evidence that MLR response is decreasing in market share in the group segment.

Table 8: Heterogeneity Results by Market Structure: Individual Market, Binary Treatment

\begin{tabular}{|c|c|c|c|c|c|c|}
\hline & \multicolumn{2}{|c|}{ MLR } & \multicolumn{2}{|c|}{$\ln$ (Claims) } & \multicolumn{2}{|c|}{$\ln ($ Premiums $)$} \\
\hline & (1) & $(2)$ & $(3)$ & (4) & $(5)$ & $(6)$ \\
\hline Post- $2011 *$ Treatment & $\begin{array}{c}0.081 \\
(0.023)^{* * *}\end{array}$ & $\begin{array}{c}0.081 \\
(0.026)^{* * *}\end{array}$ & $\begin{array}{c}0.079 \\
(0.049)\end{array}$ & $\begin{array}{c}0.055 \\
(0.061)\end{array}$ & $\begin{array}{l}-0.031 \\
(0.042)\end{array}$ & $\begin{array}{l}-0.055 \\
(0.049)\end{array}$ \\
\hline Post-2011 * Treatment $*$ MktShare & $\begin{array}{l}-0.014 \\
(0.028)\end{array}$ & & $\begin{array}{l}-0.018 \\
(0.059)\end{array}$ & & $\begin{array}{c}0.009 \\
(0.060)\end{array}$ & \\
\hline Post-2011 $*$ Treatment $* H H I$ & & $\begin{array}{l}-0.013 \\
(0.035)\end{array}$ & & $\begin{array}{c}0.023 \\
(0.079)\end{array}$ & & $\begin{array}{c}0.053 \\
(0.078)\end{array}$ \\
\hline Interaction var. mean & .2861 & .5282 & .2861 & .5282 & .2861 & .5282 \\
\hline$R^{2}$ & 0.75 & 0.75 & 0.89 & 0.89 & 0.86 & 0.86 \\
\hline \# Insurers & 184 & 184 & 184 & 184 & 184 & 184 \\
\hline Observations & 1,417 & 1,417 & 1,417 & 1,417 & 1,417 & 1,417 \\
\hline
\end{tabular}

Note: Regressions are weighted by enrollment, and standard errors are clustered by insurer. All specifications include year fixed effects, insurer fixed effects, and a treatment group linear time trend. The outcome variables Claims and Premiums are measured on a per life-year basis. HHI is divided by 10,000 so that the HHI variable ranges between 0 and 1 . Treatment $\equiv \mathbb{1}\left\{\hat{d}_{i}>0\right\} .{ }^{*} \mathrm{p}<0.10,{ }^{*} \mathrm{p}<0.05,{ }^{* * *} \mathrm{p}<.01$.

Our results are generally robust to different metrics used to define treatment, as presented in Appendix B.1. One can vary the set of years used to predict whether a firm's target MLR $\hat{m}_{i}$ was below the regulatory threshold in 2011; in our main analyses, we have used 2006-2010. Tables B.4-B.7 in Appendix B.1 present results from our main specifications for both markets and for both the binary or continuous treatment definitions using data from windows leading up to 2010 of varying width (including 2010 alone) to predict treatment status. Our results are quite robust to these variations. The results are also robust to the number of pre-period observations a firm was required to have in order to predict whether or not it would be treated by the new MLR regulations. One potential concern is that a single measurement during the 20062010 period might be a poor predictor of what the firm's MLR would be in 2011, and thereby provide a particularly noisy measure of which firms are actually treated (not to mention one 
which would be more likely subject to mean reversion). In our main analyses presented above, we require firms to have only one pre-period observation. Tables B.8-B.11 in Appendix B.2 present results for specifications that vary the required number of pre-period observations on which to base our treatment variable between 2 and 4 . Again, the results are not sensitive to which method is used. Finally, we pursue an instrumental variables strategy in Section B.3 to account for noise in the definition of treatment. We create one estimate for a firm's treatment status using data from 2006-2008 and another using data from 2009-2010. We instrument for the 2009-2010 measure with the 2006-2008 measure. In principle, this strategy isolates the signal from the noise in our predicted treatment variable and provides estimates free of measurement error. Our IV estimates are generally quite similar to our OLS estimates, again suggesting that measurement error is not playing a major role in our results.

\section{Effects on Enrollment}

One way that we can investigate whether treated and untreated firms were differentially impacted by concurrent ACA regulations, such as the requirement to extend coverage to dependents up to age 26 , is to test whether our treated firms experienced differential changes in enrollment in the post period. This analysis is also useful for gauging the potential extent to which insurers might have complied with the MLR rule by selecting higher-risk individuals, increasing the "quality" of their insurance products (and thus attracting greater demand), or concurrent changes in the industry that might confound our estimates.

Table 9 presents the results of estimating equation (6) with the natural log of enrollment as the outcome variable. Our point estimate is that enrollment increased disproportionately among treated insurers in both segments, but we are unable to reject a null effect due to imprecision. One pattern that is reassuring (though also not statistically significant) is that this enrollment increase does not become stronger over time, suggesting it is not driving our estimates of rising claims costs among treated insurers. To gauge the extent to which a differential increase in enrollment could explain our results, suppose treated insurers experienced an increase in enrollment of $20 \%$, at the upper end of what our point estimates fail to reject. In order for a $20 \%$ increase in enrollment to explain a $7 \%$ increase in claims costs, the new enrollees would have to be $42 \%$ sicker than the incumbent population. This change in risk pool health would have to become even stronger over time. However, the contemporaneous changes that occurred with the implementation of the $80 / 20$ rule were the extension of coverage to dependents under 26 (which would likely pull claims per life-year down) and coverage of preventive care. We view these offsetting effects as unlikely to explain the observed cost changes. 
Table 9: Regression Results: Enrollment, Binary Treatment

\begin{tabular}{|c|c|c|c|c|}
\hline & \multicolumn{2}{|c|}{ Individual } & \multicolumn{2}{|c|}{ Group } \\
\hline & (1) & $(2)$ & (3) & (4) \\
\hline Post-2011 * Treatment & $\begin{array}{c}0.072 \\
(0.089)\end{array}$ & & $\begin{array}{c}0.060 \\
(0.063)\end{array}$ & \\
\hline $2011 *$ Treatment & & $\begin{array}{c}0.081 \\
(0.072)\end{array}$ & & $\begin{array}{c}0.087 \\
(0.052)^{*}\end{array}$ \\
\hline $2012 *$ Treatment & & $\begin{array}{c}0.052 \\
(0.120)\end{array}$ & & $\begin{array}{c}0.018 \\
(0.087)\end{array}$ \\
\hline $2013 *$ Treatment & & $\begin{array}{c}0.083 \\
(0.164) \\
\end{array}$ & & $\begin{array}{c}0.040 \\
(0.113) \\
\end{array}$ \\
\hline$R^{2}$ & 0.91 & 0.91 & 0.92 & 0.92 \\
\hline \# Insurers & 184 & 184 & 406 & 406 \\
\hline Observations & 1,417 & 1,417 & 3,295 & 3,295 \\
\hline
\end{tabular}

\section{Cost-Reducing Effort and Utilization}

Our theory predicts that minimum MLR regulations will reduce insurers' incentives to keep claims costs down, both by encouraging a lower price per dollar of insurance (and thus more comprehensive coverage) and paying higher prices for medical services. We now present suggestive evidence of these mechanisms at work using data on two additional outcomes: administrative expenses and Quality Improvement expenditures. A key limitation of our data on these measures is that reporting only began in $2010 .{ }^{30}$ We therefore present these results as merely suggestive because we are unable to examine preexisting differential trends across the treatment and control insurers that might be driving the results.

Administrative expenses are insurers' non-medical costs for items such as salaries and advertising, which much like the cost of effort $\psi(e)$ in our model, are not allowed to enter the numerator of the MLR calculation. Thus, the portion of premium revenue that is not spent paying medical claims (at most $20 \%$ or $15 \%$ under MLR regulation) must be split between administrative expenses and profits. As of 2010, administrative costs represent approximately $10 \%$ of total premiums revenue, and thus the balance represents insurer profit margins. To the extent that administrative spending reflect the direct costs of managing care or negotiating

${ }^{30}$ Other utilization measures reported to NAIC throughout the study period are sufficiently noisy that we are unable to reject large changes (positive or negative). 
provider prices, our theory predicts that such spending should fall when the minimum MLR regulation binds.

As described in section II, qualifying Quality Improvement (QI) expenditures are defined as insurer expenses to directly improve enrollee health outcomes (such as programs to reduce medical errors and prevent hospital readmission). These are considered medical claims for the purpose of MLR calculation under the ACA, and thus enter the numerator of MLR. To the extent that there are certain administrative expenses that could be considered QI, one would suspect there might be some relabelling in pursuit of MLR compliance. However, QI expenditures are generally small, representing about $1 \%$ of premiums, so it would be difficult to make a material change in MLR without substantially increasing QI expenditures, which could raise red flags. We nonetheless expect such expenses to increase when the regulation binds.

Tables 10 and 11 present the results of our main specifications for the individual and group markets, respectively, using our binary definition of treatment based on historical MLRs during the 2006-2010 period. Now, however, the sample only exists between 2010-2013, and thus the baseline period is only 2010. ${ }^{31}$ Because this data was collected for ACA MLR regulation compliance, we are now able to separately measure outcomes for the large and small group markets. While the results generally lack precision, the signs are consistent across both segments: QI spending goes up, and administrative costs fall.

Given that administrative costs account for a roughly 10 times larger portion of premium revenue than does QI, the fall in administrative costs is substantially larger than the increase in QI expenditures, supporting the notion that this is not simply an exercise in relabelling. Instead, the results are consistent with a fall in the marginal product of claims cost-reducing activities that are costly to undertake, leading insurers to scale back these efforts. We again caution that these estimates omit the treatment group-specific trends included in our main results.

31 This data is pulled from the NAIC Supplemental Health Care Exhibit. 
Table 10: Impacts on Other Outcomes, Individual Market

\begin{tabular}{lccccc}
\hline & \multicolumn{2}{c}{$\ln (\mathrm{QI}$ Spending $)$} & \multicolumn{2}{c}{$\ln ($ Admin. Costs $)$} \\
\cline { 2 - 3 } \cline { 5 - 6 } & $(1)$ & $(2)$ & & $(3)$ & $(4)$ \\
\hline Post-2011 * Treatment & 0.149 & & -0.148 & \\
& $(0.128)$ & & $(0.089)^{*}$ & \\
$2011 *$ Treatment & & 0.049 & & -0.195 \\
& & $(0.093)$ & & $(0.066)^{* * *}$ \\
$2012 *$ Treatment & & 0.025 & & -0.180 \\
& & $(0.131)$ & & $(0.084)^{* *}$ \\
$2013 *$ Treatment & & 0.372 & & -0.070 \\
& & $(0.218)^{*}$ & & $(0.139)$ \\
\hline Mean Share of 2010 Premiums & .01 & .01 & .13 & .13 \\
$R^{2}$ & 0.76 & 0.77 & 0.80 & 0.80 \\
\# Insurers & 171 & 171 & 171 & 171 \\
Observations & 619 & 619 & 620 & 620 \\
\hline
\end{tabular}

Note: The dependent variable is given in the column headings ("QI Spending" is Quality Improvement Spending, and "Admin. Costs" are administrative costs). All dependent variables are on per life-year basis. Regressions are weighted by enrollment, and standard errors are clustered by insurer. All specifications include insurer and year fixed effects.

Treatment $\equiv \mathbb{1}\left\{\hat{d}_{i}>0\right\} .{ }^{*} \mathrm{p}<0.10,{ }^{* *} \mathrm{p}<0.05,{ }^{* * *} \mathrm{p}<.01$. 
Table 11: Impacts on Other Outcomes, Group Markets

\begin{tabular}{|c|c|c|c|c|}
\hline & \multicolumn{2}{|c|}{$\ln ($ QI Spending) } & \multicolumn{2}{|c|}{$\ln$ (Admin. Costs) } \\
\hline & (1) & $(2)$ & $(3)$ & $(4)$ \\
\hline \multicolumn{5}{|l|}{ Panel A: Small Group } \\
\hline Post-2011* Treatment & $\begin{array}{c}0.175 \\
(0.151)\end{array}$ & & $\begin{array}{l}-0.050 \\
(0.063)\end{array}$ & \\
\hline $2011 *$ Treatment & & $\begin{array}{c}0.264 \\
(0.149)^{*}\end{array}$ & & $\begin{array}{c}-0.051 \\
(0.064)\end{array}$ \\
\hline $2012 *$ Treatment & & $\begin{array}{c}0.133 \\
(0.154)\end{array}$ & & $\begin{array}{c}-0.033 \\
(0.067)\end{array}$ \\
\hline $2013 *$ Treatment & & $\begin{array}{c}0.115 \\
(0.177)\end{array}$ & & $\begin{array}{c}-0.065 \\
(0.105)\end{array}$ \\
\hline Mean Share of 2010 Premiums & .01 & .01 & .09 & .09 \\
\hline$R^{2}$ & 0.81 & 0.81 & 0.82 & 0.83 \\
\hline \# Insurers & 336 & 336 & 336 & 336 \\
\hline Observations & 1,127 & 1,127 & 1,164 & 1,164 \\
\hline \multicolumn{5}{|l|}{ Panel B: Large Group } \\
\hline Post-2011 * Treatment & $\begin{array}{c}0.087 \\
(0.148)\end{array}$ & & $\begin{array}{l}-0.100 \\
(0.080)\end{array}$ & \\
\hline $2011 *$ Treatment & & $\begin{array}{c}0.152 \\
(0.136)\end{array}$ & & $\begin{array}{c}-0.057 \\
(0.084)\end{array}$ \\
\hline $2012 *$ Treatment & & $\begin{array}{c}0.067 \\
(0.144)\end{array}$ & & $\begin{array}{c}-0.097 \\
(0.091)\end{array}$ \\
\hline $2013 *$ Treatment & & $\begin{array}{c}0.038 \\
(0.182) \\
\end{array}$ & & $\begin{array}{c}-0.145 \\
(0.081)^{*}\end{array}$ \\
\hline Mean Share of 2010 Premiums & .01 & .01 & .06 & .06 \\
\hline$R^{2}$ & 0.78 & 0.78 & 0.83 & 0.83 \\
\hline \# Insurers & 373 & 373 & 373 & 373 \\
\hline Observations & 1,285 & 1,285 & 1,320 & 1,320 \\
\hline
\end{tabular}

Note: The dependent variable is given in the column headings ("QI Spending" is Quality Improvement Spending, and "Admin. Costs" are administrative costs). All dependent variables are on a per life-year basis. Regressions are weighted by enrollment, and standard errors are clustered by insurer. All specifications include insurer and year fixed effects. The top panel shows results for the small group market, and the bottom panel shows the large group market. Treatment $\equiv \mathbb{1}\left\{\hat{d}_{i}>0\right\}$. ${ }^{*} \mathrm{p}<0.10,{ }^{*} \mathrm{p}<0.05,{ }^{* * *}$ $\mathrm{p}<.01$. 


\section{Conclusion}

This paper connects regulations of actuarial fairness to cost of service regulation, and uses the recently-implemented ' $80 / 20$ ' rule in the ACA to estimate the role these forces play in the determination of claims costs and premiums in the market for health insurance. The 80/20 rule requires health insurers in the commercial, fully-insured market to keep the share of their premium revenue spent on medical claims, known as the Medical Loss Ratio (MLR), above a minimum threshold, and to rebate the difference to customers if they fall short of this minimum. We find robust evidence that insurers increased their MLRs to comply with the regulation, and that this increase came largely by increases in claims costs, not premium reductions.

We find that insurers in the individual market were most strongly impacted by the $80 / 20$ rule, with affected insurers increasing their claims costs $7 \%$ on average and as much as $11 \%$ after two years of adjustment. We find that the rule also resulted in higher MLRs and claims costs in the group market, though the regulation was less binding in this segment. We generally find that the magnitude of the increase in claims costs scales with the initial distance from the minimum threshold. These results stand in stark contrast to the original intention of the rule: lower premiums. We do not find that insurers lowered premiums as a means to increase their MLR.

Although the exact mechanism by which insurers increased claims costs remains unclear, we believe there are three possible explanations: (1) affected insurers experienced a decline in the health of their insured populations, (2) affected insurers increased the "quality" or generosity of their insurance products, or (3) affected insurers reduced costly efficiency effort and thus increased input costs, holding services fixed. Concurrent industry changes such as requiring coverage of dependents under 26 years old and mandatory coverage of preventative care potentially have impacts parallel with explanation (1) to the extent such rules fell disproportionately on historically low-MLR insurers. Our results on enrollment changes suggest that route (1) is unlikely: if we were to suppose an even $20 \%$ increase in enrollment (at the upper end of what our data can fail to reject, given imprecise estimates), these individuals would have to be $42 \%$ sicker than the average policyholder to explain our changes in costs. Given that 26 year olds are likely to be relatively healthy, this requires an extraordinary amount of preventive care among just the right insurers to explain our results.

Instead, it is more likely that insurers raised their claims costs from a combination of more comprehensive coverage and reduced cost-containment effort, such as negotiations with providers or claims utilization management practices. While the difference between these two mechanisms is pivotal for interpreting the welfare effects of the regulation, our utilization data is too noisy to directly measure which of these two explanations is more likely. As an indirect measure, 
we consistently find across market segments that insurers with historically low MLRs reduced their administrative expenses when minimum MLR rules were instituted. This is consistent with a fall in the value of cost-reducing effort once profits and costs are coupled by regulatory constraint.

The implications for this sort of regulatory mechanism in health care are substantial. Although a relatively small share of the population was directly impacted by the $80 / 20$ rule, our results suggest minimum MLR regulations have played an important role in shaping incentives in health care to the extent that many insurers were already above the threshold due to similar regulations already in place at the state level. A robust literature has grown out of the original insights that cost of service regulation distorts firm incentives in the utilities sector. Drawing parallels between this form of regulation and rules in force for health insurers raises the possibility of transferring some of those lessons over to reduce the cost of care. 


\section{References}

Abraham, Jean M. and Pinar Karaca-Mandic, "Regulating the Medical Loss Ratio: Implications for the Individual Market," American Journal of Managed Care, 2011, 17 (3), 211-218.

_ , _ , and Kosali Simon, "How has the Affordable Care Act's Medical Loss Ratio Regulation Affected Insurer Behavior?," Medical care, 2014, 52 (4), 370-7.

Acemoglu, Daron and Amy Finkelstein, "Input and Technology Choices in Regulated Industries: Evidence From the Health Care Sector," Journal of Political Economy, 2008, 116 (5), 837-880.

America's Health Insurance Plans, "State Mandatory Medical Loss Ratio (MLR) Requirements for Comprehensive, Major Medical Coverage: Summary of State Laws and Regulations," Technical Report November 1998, America's Health Insurance Plans 2010.

Antwi, By Yaa Akosa, Asako S. Moriya, and Kosali Simon, "Effects of federal policy to insure young adults: Evidence from the 2010 affordable care act's dependent-coverage mandate," American Economic Journal: Economic Policy, 2013, 5 (4), 1-28.

Averch, Harvey and Leland L. Johnson, "Behavior of the Firm Under Regulatory Constraint," The American Economic Review, 1962, 52 (5), 1052-1069.

Cabral, Marika, Michael Geruso, and Neale Mahoney, "Does Privatized Health Insurance Benefit Patients or Producers? Evidence from Medicare Advantage," 2015.

Cicala, Steve, "When Does Regulation Distort Costs? Lessons from Fuel Procurement in U.S. Electricity Generation," American Economic Review, 2015, 105 (1), 411-444.

Clemans-Cope, Lisa, Bowen Garrett, and Doug Wissoker, "Health Insurer Responses to Medical Loss Ratio Regulation: Increased Efficiency and Value to Consumers," Technical Report May, Urban Institute 2015.

Clemens, Jeffrey and Joshua D. Gottlieb, "Do Physicians' Financial Incentives Affect Medical Treatment and Patient Health?," American Economic Review, 2014, 104 (4), 13201349.

_ and _ , "In the Shadow of a Giant: Medicare's Influence on Private Physician Payments," Journal of Political Economy, 2017, 125 (1), 1-39.

_ , Joshua Gottlieb, and Tímea Laura Molnár, "The Anatomy of Physician Payments: Contracting Subject to Complexity," 2015. 
Dafny, Leemore and Subramaniam Ramanarayanan, "Does it Matter if Your Health Insurer is For-Profit? Effects of Ownership on Premiums, Insurance Coverage, and Medical Spending," 2012.

Depew, Briggs and James Bailey, "Did the Affordable Care Act's dependent coverage mandate increase premiums?," Journal of Health Economics, 2015, 41, 1-14.

Dranove, David, Mark Shanley, and William D. White, "Price and Concentration in Hospital Markets: The Switch from Patient-Driven to Payer-Driven Competition," Journal of Law and Economics, 1993, 36 (1), 179-204.

Duggan, Mark and Fiona M. Scott Morton, "The Distortionary Effects of Government Procurement: Evidence from Medicaid Prescription Drug Purchasing," Quarterly Journal of Economics, 2006, 121 (1), 1-30.

Einav, Liran, Amy Finkelstein, and Neale Mahoney, "Provider Incentives and Health Care Costs: Evidence from Long-Term Care Hospitals," 2017.

Ericson, Keith M Marzilli and Amanda Starc, "Pricing Regulation and Imperfect Competition on the Massachusetts Health Insurance Exchange," The Review of Economics and Statistics, 2015, 97 (3), 667-682.

Fowlie, Meredith L., "Emissions Trading, Electricity Restructuring, and Investment in Pollution Abatement," The American Economic Review, 2010, 100 (3), 837-869.

Harrington, Scott E., "Medical Loss Ratio Regulation Under the Affordable Care Act," Inquiry (United States), 2013, 50 (1), 9-26.

Henry J. Kaiser Family Foundation, "Summary of the Affordable Care Act," Technical Report 2013.

- and Health Research \& Educational Trust, "Employer Health Benefits Annual Survey," Technical Report 2015.

Ho, Katherine, "Insurer-provider networks in the medical care market," American Economic Review, 2009, 99 (1), 393-430.

Karaca-Mandic, Pinar, Jean M. Abraham, and Kosali Simon, "Is the Medical Loss Ratio a Good Target Measure for Regulation in the Individual Market for Health Insurance?," Health Economics, 2015, 24 (1), 55-74.

Kirchhoff, Suzanne M, "Medical Loss Ratio Requirements Under the Patient Protection and Affordable Care Act," 2014, 1. 
Laffont, Jean-Jacques and Jean Tirole, A Theory of Incentives in Procurement and Regulation, MIT Press, 1993.

Lieber, Ethan M.J., "Does Health Insurance Coverage Fall when Nonprofit Insurers Become For-Profits?," 2017.

McCue, Michael J. and Mark A. Hall, "Health Insurers' Financial Performance and Quality Improvement Expenditures in the Affordable Care Act's Second Year," Medical Care Research and Review, 2015, 72 (1), 113-122.

_ , _ , and Xinliang Liu, "Impact of Medical Loss Regulation on the Financial Performance of Health Insurers," Health Affairs, 2013, 32 (9), 1546-1551.

Norton, Edward C. and Douglas O Staiger, "How hospital ownership affects access to care for the uninsured.," The RAND Journal of Economics, 1994, 25 (1), 171-85.

Picone, Gabriel, Shin yi Chou, and Frank Sloan, "Are for-profit hospital conversions harmful to patients and to Medicare?," The Rand journal of economics, 2002, 33 (3), 507523.

Sloan, Frank A., "Chapter 21 Not-for-profit ownership and hospital behavior," 2000.

Starc, Amanda, "Insurer pricing and consumer welfare: Evidence from Medigap," RAND Journal of Economics, 2014, 45 (1), 198-220.

The Centers for Medicare \& Medicaid Services, "Consumers Benefitted From 80/20 Rule in 2013," Technical Report 2014.

_, "Medical Loss Ratio (MLR) Annual Reporting Form Filing Instructions for the 2014 MLR Reporting Year Table," Technical Report 2014. 


\section{Appendix A Theory Appendix}

\section{Proof of Proposition 1}

Let $k^{M}$ denote the MLR of the unregulated monopolist, so that the constraint of (3) would just bind if it were mandated as the minimum allowable MLR. Then the change in effort with the introduction of MLR regulation $k$ is

$$
e^{R}(k)-e^{M}=\int_{k^{M}}^{k} \frac{d e}{d \kappa} d \kappa
$$

Total differentiation of the first order condition of (3), having substituted the constraint for an unconstrained function of $e$ yields

$$
\frac{d e}{d k}=\left\{\frac{\left[q(p)+p q^{\prime}(p)\right]+(1-k) p\left[2 q^{\prime}(p)+p q^{\prime \prime}(p)\right]}{k^{2} \psi^{\prime \prime}(e)-(1-k)\left[2 q^{\prime}(p)+p q^{\prime \prime}(p)\right]}\right\}
$$

In the numerator, the first term in brackets is negative from the first order condition since $\psi^{\prime}(e)>0$ and $k \in(0,1)$. The sign of the second term depends on the second derivative of premium revenue with respect to price, which must be negative for the unconstrained monopolist's objective function to be concave (i.e., downward sloping marginal revenue). The denominator is the opposite sign of the second order condition, and is therefore positive for the regulated insurer's solution to be a maximum. Effort is therefore declining in the MLR regulation whenever the constraint binds, so that $e^{R}(k)-e^{M}<0$ so long as the insurer's decision is affected by the regulation

\section{Proof of Proposition 2}

The derivative of total insurer claims, $C \equiv(\beta-e) q(p)$ with respect to $k$, assuming a binding constraint is

$$
\frac{d C}{d k}=-q(p)\left\{\varepsilon^{D}\left[p+\frac{d e}{d k}\right]+\frac{d e}{d k}\right\}
$$

after substituing equation (4) in for $\frac{d p}{d k}$, and letting $\varepsilon^{D}<-1$ denote the elasticity of demand. Then insurer claims will rise with $k$ so long as the expression in the braces is negative. Suppose instead that this term in braces were positive, so that

$$
\varepsilon^{D}>-\frac{\frac{d e}{d k}}{\left[p+\frac{d e}{d k}\right]}=-\frac{\left[q(p)+p q^{\prime}(p)\right]+(1-k) p\left[2 q^{\prime}(p)+p q^{\prime \prime}(p)\right]}{\left[q(p)+p q^{\prime}(p)\right]+p k^{2} \psi^{\prime \prime}(e)}
$$


However, the second order condition requires that $(1-k)\left[2 q^{\prime}(p)+p q^{\prime \prime}(p)\right]-k^{2} \psi^{\prime \prime}(e)<0$ for a maximum. Some rearranging of the second order condition shows that the right hand side of (7) is greater than minus one in magnitude, in contradiction of the requirement that demand be elastic. $\frac{d C}{d k}$ is therefore positive so long as the regulatory constraint is binding. 


\section{Appendix B Sensitivity Analysis and Ancillary Results}

\section{B.1 Sensitivity Results: Adding Fixed-Effects and Excluding Non-profits}

Table B.1: Sensitivity Results: Individual Market, Continuous Treatment

\begin{tabular}{|c|c|c|c|c|c|c|}
\hline & \multicolumn{6}{|c|}{ MLR } \\
\hline & (1) & $(2)$ & (3) & (4) & (5) & (6) \\
\hline Post- $2011 *$ Treatment & $\begin{array}{c}0.695 \\
(0.117)^{* * *}\end{array}$ & & $\begin{array}{c}0.599 \\
(0.155)^{* * *}\end{array}$ & & $\begin{array}{c}0.681 \\
(0.119)^{* * *}\end{array}$ & \\
\hline $2011 *$ Treatment & & $\begin{array}{c}0.598 \\
(0.120)^{* * *}\end{array}$ & & $\begin{array}{c}0.473 \\
(0.164)^{* * *}\end{array}$ & & $\begin{array}{c}0.555 \\
(0.121)^{* * *}\end{array}$ \\
\hline $2012 *$ Treatment & & $\begin{array}{c}0.718 \\
(0.112)^{* * *}\end{array}$ & & $\begin{array}{c}0.635 \\
(0.198)^{* * *}\end{array}$ & & $\begin{array}{c}0.694 \\
(0.120)^{* * *}\end{array}$ \\
\hline $2013 *$ Treatment & & $\begin{array}{c}0.836 \\
(0.162)^{* * *}\end{array}$ & & $\begin{array}{c}0.833 \\
(0.181)^{* * *}\end{array}$ & & $\begin{array}{c}0.853 \\
(0.160)^{* * *}\end{array}$ \\
\hline State-by-year f.e. & No & No & Yes & Yes & No & No \\
\hline Exclude nonprofits & No & No & No & No & Yes & Yes \\
\hline$R^{2}$ & 0.75 & 0.76 & 0.85 & 0.85 & 0.72 & 0.72 \\
\hline \# Insurers & 183 & 183 & 183 & 183 & 125 & 125 \\
\hline Observations & 1,412 & 1,412 & 1,412 & 1,412 & 926 & 926 \\
\hline
\end{tabular}

Note: The dependent variable in all columns is MLR. Columns (1) and (2) reproduce results from our main specification. Columns (3) and (4) include state-by-year fixed effects. Columns (5) and (6) drop insurers that were ever nonprofits. Regressions are weighted by enrollment, and standard errors are clustered by insurer. All specifications include insurer fixed effects and a treatment group linear time trend.

Treatment $\equiv \hat{d}_{i} * \mathbb{1}\left\{\hat{d}_{i}>0\right\} . * \mathrm{p}<0.10, * * \mathrm{p}<0.05, * * * \mathrm{p}<.01$. 
Table B.2: Sensitivity Results: Group Market, Binary Treatment

\begin{tabular}{lcccccc}
\hline & \multicolumn{5}{c}{ MLR } \\
\cline { 2 - 6 } & $(1)$ & $(2)$ & $(3)$ & $(4)$ & $(5)$ & $(6)$ \\
\hline Post-2011 * Treatment & 0.015 & & 0.010 & & 0.015 & \\
& $(0.007)^{* *}$ & & $(0.008)$ & & $(0.008)^{*}$ & \\
$2011 *$ Treatment & & 0.011 & & 0.009 & & 0.011 \\
& & $(0.007)$ & & $(0.008)$ & & $(0.008)$ \\
$2012 *$ Treatment & & 0.017 & & 0.009 & & 0.018 \\
& & $(0.009)^{*}$ & & $(0.010)$ & & $(0.009)^{*}$ \\
$2013 *$ Treatment & & 0.023 & & 0.020 & & 0.027 \\
& & $(0.009)^{* *}$ & & $(0.010)^{*}$ & & $(0.010)^{* * *}$ \\
\hline State-by-year f.e. & No & No & Yes & Yes & No & No \\
Exclude nonprofits & No & No & No & No & Yes & Yes \\
\hline$R^{2}$ & 0.69 & 0.69 & 0.77 & 0.77 & 0.69 & 0.69 \\
\# Insurers & 402 & 402 & 402 & 402 & 312 & 312 \\
Observations & 3,277 & 3,277 & 3,277 & 3,277 & 2,500 & 2,500 \\
\hline
\end{tabular}

Note: The dependent variable in all columns is MLR. Columns (1) and (2) reproduce results from our main specification. Columns (3) and (4) include state-by-year fixed effects. Columns (5) and (6) drop insurers that were ever nonprofits. Regressions are weighted by enrollment, and standard errors are clustered by insurer. All specifications include insurer fixed effects and a treatment group linear time trend. Treatment $\equiv \mathbb{1}\left\{\hat{d}_{i}>0\right\} . *$ $\mathrm{p}<0.10, * * \mathrm{p}<0.05, * * * \mathrm{p}<.01$.

Table B.3: Sensitivity Results: Group Market, Continuous Treatment

\begin{tabular}{lcccccc}
\hline & \multicolumn{5}{c}{ MLR } \\
\cline { 2 - 6 } & $(1)$ & $(2)$ & $(3)$ & $(4)$ & $(5)$ & $(6)$ \\
\hline Post-2011 * Treatment & 0.523 & & 0.411 & & 0.534 & \\
& $(0.123)^{* * *}$ & & $(0.165)^{* *}$ & & $(0.126)^{* * *}$ & \\
$2011 *$ Treatment & & 0.464 & & 0.441 & & 0.465 \\
& & $(0.117)^{* * *}$ & & $(0.164)^{* * *}$ & & $(0.123)^{* * *}$ \\
$2012 *$ Treatment & & 0.502 & & 0.297 & & 0.501 \\
& & $(0.142)^{* * *}$ & & $(0.188)$ & & $(0.147)^{* * *}$ \\
$2013 *$ Treatment & & 0.634 & & 0.511 & & 0.670 \\
& & $(0.146)^{* * *}$ & & $(0.173)^{* * *}$ & & $(0.152)^{* * *}$ \\
\hline State-by-year f.e. & No & No & Yes & Yes & No & No \\
Exclude nonprofits & No & No & No & No & Yes & Yes \\
\hline$R^{2}$ & 0.70 & 0.70 & 0.77 & 0.77 & 0.70 & 0.70 \\
$\#$ Insurers & 402 & 402 & 402 & 402 & 312 & 312 \\
Observations & 3,277 & 3,277 & 3,277 & 3,277 & 2,500 & 2,500 \\
\hline
\end{tabular}

Note: The dependent variable in all columns is MLR. Columns (1) and (2) reproduce results from our main specification. Columns (3) and (4) include state-by-year fixed effects. Columns (5) and (6) drop insurers that were ever nonprofits. Regressions are weighted by enrollment, and standard errors are clustered by insurer. All specifications include insurer fixed effects and a treatment group linear time trend.

Treatment $\equiv \hat{d}_{i} * \mathbb{1}\left\{\hat{d}_{i}>0\right\} .{ }^{*} \mathrm{p}<0.10,{ }^{* *} \mathrm{p}<0.05, * * * \mathrm{p}<.01$. 


\section{B.2 Sensitivity Results: Varying Years Used to Determine Treatment}

Table B.4: Regression Results: Individual Market, Binary Treatment using Different Years to Determine Treatment

\begin{tabular}{|c|c|c|c|c|c|c|c|c|c|c|c|c|}
\hline & \multicolumn{2}{|c|}{ 2005-2010 } & \multicolumn{2}{|c|}{ 2006-2010 } & \multicolumn{2}{|c|}{ 2007-2010 } & \multicolumn{2}{|c|}{ 2008-2010 } & \multicolumn{2}{|c|}{ 2009-2010 } & \multicolumn{2}{|c|}{2010 only } \\
\hline & (1) & (2) & (3) & (4) & (5) & (6) & (7) & (8) & (9) & (10) & (11) & (12) \\
\hline Post-2011 * Treatment & $\begin{array}{c}0.072 \\
(0.018)^{* * *}\end{array}$ & & $\begin{array}{c}0.073 \\
(0.018)^{* * *}\end{array}$ & & $\begin{array}{c}0.083 \\
(0.018)^{* * *}\end{array}$ & & $\begin{array}{c}0.082 \\
(0.018)^{* * *}\end{array}$ & & $\begin{array}{c}0.080 \\
(0.018)^{* * *}\end{array}$ & & $\begin{array}{c}0.082 \\
(0.018)^{* * *}\end{array}$ & \\
\hline $2011 *$ Treatment & & $\begin{array}{c}0.065 \\
(0.017)^{* * *}\end{array}$ & & $\begin{array}{c}0.066 \\
(0.017)^{* * *}\end{array}$ & & $\begin{array}{c}0.074 \\
(0.018)^{* * *}\end{array}$ & & $\begin{array}{c}0.073 \\
(0.018)^{* * *}\end{array}$ & & $\begin{array}{c}0.072 \\
(0.018)^{* * *}\end{array}$ & & $\begin{array}{c}0.071 \\
(0.018)^{* * *}\end{array}$ \\
\hline $2012 *$ Treatment & & $\begin{array}{c}0.081 \\
(0.020)^{* * *}\end{array}$ & & $\begin{array}{c}0.082 \\
(0.020)^{* * *}\end{array}$ & & $\begin{array}{c}0.093 \\
(0.020)^{* * *}\end{array}$ & & $\begin{array}{c}0.091 \\
(0.021)^{* * *}\end{array}$ & & $\begin{array}{c}0.091 \\
(0.021)^{* * *}\end{array}$ & & $\begin{array}{c}0.096 \\
(0.020)^{* * *}\end{array}$ \\
\hline $2013 *$ Treatment & & $\begin{array}{c}0.094 \\
(0.025)^{* * *}\end{array}$ & & $\begin{array}{c}0.094 \\
(0.025)^{* * *}\end{array}$ & & $\begin{array}{c}0.109 \\
(0.026)^{* * *}\end{array}$ & & $\begin{array}{c}0.107 \\
(0.027)^{* * *}\end{array}$ & & $\begin{array}{c}0.104 \\
(0.027)^{* * *}\end{array}$ & & $\begin{array}{c}0.109 \\
(0.026)^{* * *}\end{array}$ \\
\hline$R^{2}$ & 0.75 & 0.75 & 0.75 & 0.75 & 0.75 & 0.75 & 0.75 & 0.75 & 0.75 & 0.75 & 0.75 & 0.75 \\
\hline \# Inst & 185 & 185 & 184 & 184 & 182 & 182 & 182 & 182 & 182 & 182 & 179 & 179 \\
\hline Observations & 1,421 & 1,421 & 1,417 & 1,417 & 1,408 & 1,408 & 1,408 & 1,408 & 1,408 & 1,408 & 1,387 & 1,387 \\
\hline
\end{tabular}

Note: The dependent variable in all columns is MLR. Column headers refer to the time period used to determine treatment. All specifications include year fixed effects, insurer fixed effects, and a treatment group linear time trend. Regressions are weighted by enrollment, and standard errors are clustered by insurer. Treatment $\equiv \mathbb{1}\left\{\hat{d}_{i}>0\right\} . * \mathrm{p}<0.10, * * \mathrm{p}<0.05, * * * \mathrm{p}<.01$.

Table B.5: Regression Results: Individual Market, Continuous Treatment using Different Years to Determine Treatment

\begin{tabular}{|c|c|c|c|c|c|c|c|c|c|c|c|c|}
\hline & \multicolumn{2}{|c|}{ 2005-2010 } & \multicolumn{2}{|c|}{$2006-2010$} & \multicolumn{2}{|c|}{$2007-2010$} & \multicolumn{2}{|c|}{$2008-2010$} & \multicolumn{2}{|c|}{ 2009-2010 } & \multicolumn{2}{|c|}{2010 only } \\
\hline & (1) & (2) & (3) & (4) & (5) & (6) & (7) & (8) & (9) & (10) & (11) & (12) \\
\hline Post-2011 * Treatment & $\begin{array}{c}0.665 \\
(0.109)^{* * *}\end{array}$ & & $\begin{array}{c}0.695 \\
(0.117)^{* * *}\end{array}$ & & $\begin{array}{c}0.773 \\
(0.127)^{* * *}\end{array}$ & & $\begin{array}{c}0.770 \\
(0.119)^{* * *}\end{array}$ & & $\begin{array}{c}0.670 \\
(0.123)^{* * *}\end{array}$ & & $\begin{array}{c}0.475 \\
(0.140)^{* * *}\end{array}$ & \\
\hline $2011 *$ Treatment & & $\begin{array}{c}0.573 \\
(0.113)^{* * *}\end{array}$ & & $\begin{array}{c}0.597 \\
(0.120)^{* * *}\end{array}$ & & $\begin{array}{c}0.657 \\
(0.130)^{* * *}\end{array}$ & & $\begin{array}{c}0.659 \\
(0.121)^{* * *}\end{array}$ & & $\begin{array}{c}0.570 \\
(0.110)^{* * *}\end{array}$ & & $\begin{array}{c}0.388 \\
(0.115)^{* * *}\end{array}$ \\
\hline $2012 *$ Treatment & & $\begin{array}{c}0.695 \\
(0.106)^{* * *}\end{array}$ & & $\begin{array}{c}0.719 \\
(0.112)^{* * *}\end{array}$ & & $\begin{array}{c}0.798 \\
(0.117)^{* * *}\end{array}$ & & $\begin{array}{c}0.784 \\
(0.117)^{* * *}\end{array}$ & & $\begin{array}{c}0.683 \\
(0.149)^{* * *}\end{array}$ & & $\begin{array}{c}0.483 \\
(0.175)^{* * *}\end{array}$ \\
\hline $2013 *$ Treatment & & $\begin{array}{c}0.794 \\
(0.153)^{* * *}\end{array}$ & & $\begin{array}{c}0.835 \\
(0.162)^{* * *}\end{array}$ & & $\begin{array}{c}0.933 \\
(0.178)^{* * *}\end{array}$ & & $\begin{array}{c}0.938 \\
(0.168)^{* * *}\end{array}$ & & $\begin{array}{c}0.818 \\
(0.159)^{* * *}\end{array}$ & & $\begin{array}{c}0.609 \\
(0.174)^{* * *}\end{array}$ \\
\hline$R^{2}$ & 0.75 & 0.76 & 0.75 & 0.76 & 0.75 & 0.76 & 0.75 & 0.75 & 0.75 & 0.75 & 0.75 & 0.75 \\
\hline \# Insurers & 185 & 185 & 184 & 184 & 182 & 182 & 182 & 182 & 182 & 182 & 179 & 179 \\
\hline Observations & 1,421 & 1,421 & 1,417 & 1,417 & 1,408 & 1,408 & 1,408 & 1,408 & 1,408 & 1,408 & 1,387 & 1,387 \\
\hline
\end{tabular}

Note: The dependent variable in all columns is MLR. Column headers refer to the time period used to determine treatment. All specifications include year fixed effects, insurer fixed effects, and a treatment group linear time trend. Regressions are weighted by enrollment, and standard errors are clustered by insurer. Treatment $\equiv \hat{d}_{i} * \mathbb{1}\left\{\hat{d}_{i}>0\right\} . * \mathrm{p}<0.10, * * \mathrm{p}<0.05, * * * \mathrm{p}<.01$. 
Table B.6: Regression Results: Group Market, Binary Treatment using Different Years to Determine Treatment

\begin{tabular}{|c|c|c|c|c|c|c|c|c|c|c|c|c|}
\hline & \multicolumn{2}{|c|}{ 2005-2010 } & \multicolumn{2}{|c|}{ 2006-2010 } & \multicolumn{2}{|c|}{ 2007-2010 } & \multicolumn{2}{|c|}{ 2008-2010 } & \multicolumn{2}{|c|}{ 2009-2010 } & \multicolumn{2}{|c|}{2010 only } \\
\hline & (1) & $(2)$ & (3) & (4) & (5) & (6) & (7) & (8) & (9) & (10) & (11) & $(12)$ \\
\hline Post-2011 * Treatment & $\begin{array}{c}0.003 \\
(0.007)\end{array}$ & & $\begin{array}{c}0.015 \\
(0.007)^{* *}\end{array}$ & & $\begin{array}{c}0.022 \\
(0.008)^{* * *}\end{array}$ & & $\begin{array}{c}0.024 \\
(0.008)^{* * *}\end{array}$ & & $\begin{array}{c}0.029 \\
(0.008) * * *\end{array}$ & & $\begin{array}{c}0.013 \\
(0.007)^{*}\end{array}$ & \\
\hline $2011 *$ Treatment & & $\begin{array}{l}-0.001 \\
(0.007)\end{array}$ & & $\begin{array}{c}0.011 \\
(0.007)\end{array}$ & & $\begin{array}{c}0.019 \\
(0.008)^{* *}\end{array}$ & & $\begin{array}{c}0.020 \\
(0.008)^{* *}\end{array}$ & & $\begin{array}{c}0.027 \\
(0.007)^{* * *}\end{array}$ & & $\begin{array}{c}0.009 \\
(0.007)\end{array}$ \\
\hline $2012 *$ Treatment & & $\begin{array}{c}0.006 \\
(0.008)\end{array}$ & & $\begin{array}{c}0.017 \\
(0.009)^{*}\end{array}$ & & $\begin{array}{c}0.023 \\
(0.009)^{* *}\end{array}$ & & $\begin{array}{c}0.026 \\
(0.010)^{* * *}\end{array}$ & & $\begin{array}{c}0.028 \\
(0.010)^{* * *}\end{array}$ & & $\begin{array}{c}0.017 \\
(0.008)^{* *}\end{array}$ \\
\hline $2013 *$ Treatment & & $\begin{array}{c}0.012 \\
(0.008)\end{array}$ & & $\begin{array}{c}0.023 \\
(0.009)^{* *}\end{array}$ & & $\begin{array}{c}0.033 \\
(0.010)^{* * *}\end{array}$ & & $\begin{array}{c}0.035 \\
(0.010)^{* * *}\end{array}$ & & $\begin{array}{c}0.039 \\
(0.010)^{* * *}\end{array}$ & & $\begin{array}{c}0.024 \\
(0.009)^{* * *}\end{array}$ \\
\hline$R^{2}$ & 0.69 & 0.69 & 0.69 & 0.69 & 0.69 & 0.69 & 0.69 & 0.69 & 0.69 & 0.69 & 0.69 & 0.69 \\
\hline \# Insurers & 409 & 409 & 406 & 406 & 405 & 405 & 402 & 402 & 402 & 402 & 395 & 395 \\
\hline Observations & 3,304 & 3,304 & 3,295 & 3,295 & 3,292 & 3,292 & 3,277 & 3,277 & 3,277 & 3,277 & 3,225 & 3,225 \\
\hline
\end{tabular}

Note: The dependent variable in all columns is MLR. Column headers refer to the time period used to determine treatment. All specifications include year fixed effects, insurer fixed effects, and a treatment group linear time trend. Regressions are weighted by enrollment, and standard errors are clustered by insurer. Treatment $\equiv \mathbb{1}\left\{\hat{d}_{i}>0\right\} .{ }^{*} \mathrm{p}<0.10,{ }^{* *} \mathrm{p}<0.05,{ }^{* * *} \mathrm{p}<.01$.

Table B.7: Regression Results: Group Market, Continuous Treatment using Different Years to Determine Treatment

\begin{tabular}{|c|c|c|c|c|c|c|c|c|c|c|c|c|}
\hline & \multicolumn{2}{|c|}{$2005-2010$} & \multicolumn{2}{|c|}{$2006-2010$} & \multicolumn{2}{|c|}{$2007-2010$} & \multicolumn{2}{|c|}{ 2008-2010 } & \multicolumn{2}{|c|}{ 2009-2010 } & \multicolumn{2}{|c|}{2010 only } \\
\hline & (1) & $(2)$ & (3) & (4) & (5) & (6) & (7) & (8) & (9) & (10) & (11) & $(12)$ \\
\hline Post-2011 * Treatment & $\begin{array}{c}0.482 \\
(0.118)^{* * *}\end{array}$ & & $\begin{array}{c}0.523 \\
(0.123)^{* * *}\end{array}$ & & $\begin{array}{c}0.662 \\
(0.128)^{* * *}\end{array}$ & & $\begin{array}{c}0.538 \\
(0.156)^{* * *}\end{array}$ & & $\begin{array}{c}0.449 \\
(0.127)^{* * *}\end{array}$ & & $\begin{array}{c}0.120 \\
(0.107)\end{array}$ & \\
\hline $2011 *$ Treatment & & $\begin{array}{c}0.416 \\
(0.111)^{* * *}\end{array}$ & & $\begin{array}{c}0.464 \\
(0.117)^{* * *}\end{array}$ & & $\begin{array}{c}0.583 \\
(0.122)^{* * *}\end{array}$ & & $\begin{array}{c}0.484 \\
(0.140)^{* * *}\end{array}$ & & $\begin{array}{c}0.391 \\
(0.118)^{* * *}\end{array}$ & & $\begin{array}{r}0.085 \\
(0.104)\end{array}$ \\
\hline $2012 *$ Treatment & & $\begin{array}{c}0.461 \\
(0.141)^{* * *}\end{array}$ & & $\begin{array}{c}0.502 \\
(0.142)^{* * *}\end{array}$ & & $\begin{array}{c}0.658 \\
(0.144)^{* * *}\end{array}$ & & $\begin{array}{c}0.522 \\
(0.174)^{* * *}\end{array}$ & & $\begin{array}{c}0.438 \\
(0.138)^{* * *}\end{array}$ & & $\begin{array}{c}0.100 \\
(0.122)\end{array}$ \\
\hline $2013 *$ Treatment & & $\begin{array}{c}0.592 \\
(0.138)^{* * *}\end{array}$ & & $\begin{array}{c}0.634 \\
(0.146)^{* * *}\end{array}$ & & $\begin{array}{c}0.786 \\
(0.155)^{* * *}\end{array}$ & & $\begin{array}{c}0.640 \\
(0.195)^{* * *}\end{array}$ & & $\begin{array}{c}0.550 \\
(0.170)^{* * *}\end{array}$ & & $\begin{array}{c}0.197 \\
(0.127)\end{array}$ \\
\hline$R^{2}$ & 0.70 & 0.70 & 0.70 & 0.70 & 0.69 & 0.70 & 0.69 & 0.69 & 0.69 & 0.69 & 0.69 & 0.69 \\
\hline \# Insurers & 409 & 409 & 406 & 406 & 405 & 405 & 402 & 402 & 402 & 402 & 395 & 395 \\
\hline Observations & 3,304 & 3,304 & 3,295 & 3,295 & 3,292 & 3,292 & 3,277 & 3,277 & 3,277 & 3,277 & 3,225 & 3,225 \\
\hline
\end{tabular}

Note: The dependent variable in all columns is MLR. Column headers refer to the time period used to determine treatment. All specifications include year fixed effects, insurer fixed effects, and a treatment group linear time trend. Regressions are weighted by enrollment, and standard errors are clustered by insurer. Treatment $\equiv \hat{d}_{i} * \mathbb{1}\left\{\hat{d}_{i}>0\right\} .{ }^{*} \mathrm{p}<0.10,{ }^{* *} \mathrm{p}<0.05, * * * \mathrm{p}<.01$. 
Table B.8: Regression Results: Individual Market, Binary Treatment using Different Observations to Determine Treatment

\begin{tabular}{|c|c|c|c|c|c|c|c|c|}
\hline & \multicolumn{2}{|c|}{1 Observation } & \multicolumn{2}{|c|}{2 Observations } & \multicolumn{2}{|c|}{3 Observations } & \multicolumn{2}{|c|}{4 Observations } \\
\hline & $(1)$ & $(2)$ & $(3)$ & $(4)$ & $(5)$ & (6) & $(7)$ & $(8)$ \\
\hline Post- $2011 *$ Treatment & $\begin{array}{c}0.073 \\
(0.018)^{* * *}\end{array}$ & & $\begin{array}{c}0.072 \\
(0.018)^{* * *}\end{array}$ & & $\begin{array}{c}0.070 \\
(0.018)^{* * *}\end{array}$ & & $\begin{array}{c}0.069 \\
(0.018) * * *\end{array}$ & \\
\hline $2011 *$ Treatment & & $\begin{array}{c}0.066 \\
(0.017)^{* * *}\end{array}$ & & $\begin{array}{c}0.066 \\
(0.017)^{* * *}\end{array}$ & & $\begin{array}{c}0.063 \\
(0.018)^{* * *}\end{array}$ & & $\begin{array}{c}0.063 \\
(0.018)^{* * *}\end{array}$ \\
\hline $2012 *$ Treatment & & $\begin{array}{c}0.082 \\
(0.020)^{* * *}\end{array}$ & & $\begin{array}{c}0.078 \\
(0.020)^{* * *}\end{array}$ & & $\begin{array}{c}0.076 \\
(0.020)^{* * *}\end{array}$ & & $\begin{array}{c}0.076 \\
(0.020)^{* * *}\end{array}$ \\
\hline $2013^{*}$ Treatment & & $\begin{array}{c}0.094 \\
(0.025)^{* * *}\end{array}$ & & $\begin{array}{c}0.087 \\
(0.025)^{* * *}\end{array}$ & & $\begin{array}{c}0.088 \\
(0.026)^{* * *}\end{array}$ & & $\begin{array}{c}0.089 \\
(0.026)^{* * *}\end{array}$ \\
\hline$R^{2}$ & 0.75 & 0.75 & 0.75 & 0.75 & 0.75 & 0.75 & 0.76 & 0.77 \\
\hline \# Insurers & 184 & 184 & 168 & 168 & 158 & 158 & 141 & 141 \\
\hline Observations & 1,417 & 1,417 & 1,356 & 1,356 & 1,305 & 1,305 & 1,204 & 1,204 \\
\hline
\end{tabular}

Note: The dependent variable in all columns is MLR. The column headings indicate the minimum number of observations required to determine treatment. All specifications include year fixed effects, insurer fixed effects, and a treatment group linear time trend. Regressions are weighted by enrollment, and standard errors are clustered by insurer. Treatment $\equiv \mathbb{1}\left\{\hat{d}_{i}>0\right\} . * \mathrm{p}<0.10, * * \mathrm{p}<0.05, * * * \mathrm{p}<.01$.

Table B.9: Regression Results: Individual Market, Continuous Treatment using Different Observations to Determine Treatment

\begin{tabular}{|c|c|c|c|c|c|c|c|c|}
\hline & \multicolumn{2}{|c|}{1 Observation } & \multicolumn{2}{|c|}{2 Observations } & \multicolumn{2}{|c|}{3 Observations } & \multicolumn{2}{|c|}{4 Observations } \\
\hline & (1) & $(2)$ & (3) & (4) & (5) & (6) & (7) & (8) \\
\hline Post-2011 * Treatment & $\begin{array}{c}0.695 \\
(0.117)^{* * *}\end{array}$ & & $\begin{array}{c}0.685 \\
(0.119)^{* * *}\end{array}$ & & $\begin{array}{c}0.665 \\
(0.116)^{* * *}\end{array}$ & & $\begin{array}{c}0.681 \\
(0.124)^{* * *}\end{array}$ & \\
\hline $2011 *$ Treatment & & $\begin{array}{c}0.597 \\
(0.120)^{* * *}\end{array}$ & & $\begin{array}{c}0.617 \\
(0.129)^{* * *}\end{array}$ & & $\begin{array}{c}0.583 \\
(0.123)^{* * *}\end{array}$ & & $\begin{array}{c}0.600 \\
(0.133)^{* * *}\end{array}$ \\
\hline $2012 *$ Treatment & & $\begin{array}{c}0.719 \\
(0.112)^{* * *}\end{array}$ & & $\begin{array}{c}0.709 \\
(0.114)^{* * *}\end{array}$ & & $\begin{array}{c}0.688 \\
(0.111)^{* * *}\end{array}$ & & $\begin{array}{c}0.699 \\
(0.116)^{* * *}\end{array}$ \\
\hline $2013 *$ Treatment & & $\begin{array}{c}0.835 \\
(0.162)^{* * *}\end{array}$ & & $\begin{array}{c}0.770 \\
(0.154)^{* * *}\end{array}$ & & $\begin{array}{c}0.773 \\
(0.155)^{* * *}\end{array}$ & & $\begin{array}{c}0.793 \\
(0.165)^{* * *}\end{array}$ \\
\hline$R^{2}$ & 0.75 & 0.76 & 0.75 & 0.75 & 0.76 & 0.76 & 0.77 & 0.77 \\
\hline \# Insurers & 184 & 184 & 168 & 168 & 158 & 158 & 141 & 141 \\
\hline Observations & 1,417 & 1,417 & 1,356 & 1,356 & 1,305 & 1,305 & 1,204 & 1,204 \\
\hline
\end{tabular}

Note: The dependent variable in all columns is MLR. The column headings indicate the minimum number of observations required to determine treatment. All specifications include year fixed effects, insurer fixed effects, and a treatment group linear time trend. Regressions are weighted by enrollment, and standard errors are clustered by insurer. Treatment $\equiv \hat{d}_{i} * \mathbb{1}\left\{\hat{d}_{i}>0\right\}$. ${ }^{*} \mathrm{p}<0.10,{ }^{* *} \mathrm{p}<0.05,{ }^{* * *} \mathrm{p}<.01$. 
Table B.10: Regression Results: Group Market, Binary Treatment using Different Observations to Determine Treatment

\begin{tabular}{|c|c|c|c|c|c|c|c|c|}
\hline & \multicolumn{2}{|c|}{1 Observation } & \multicolumn{2}{|c|}{2 Observations } & \multicolumn{2}{|c|}{3 Observations } & \multicolumn{2}{|c|}{4 Observations } \\
\hline & (1) & $(2)$ & $(3)$ & $(4)$ & $(5)$ & $(6)$ & (7) & (8) \\
\hline Post-2011 * Treatment & $\begin{array}{c}0.015 \\
(0.007)^{* *}\end{array}$ & & $\begin{array}{c}0.013 \\
(0.007)^{*}\end{array}$ & & $\begin{array}{c}0.013 \\
(0.007)^{*}\end{array}$ & & $\begin{array}{c}0.013 \\
(0.007)^{*}\end{array}$ & \\
\hline $2011 *$ Treatment & & $\begin{array}{c}0.011 \\
(0.007)\end{array}$ & & $\begin{array}{c}0.010 \\
(0.008)\end{array}$ & & $\begin{array}{c}0.010 \\
(0.008)\end{array}$ & & $\begin{array}{c}0.011 \\
(0.008)\end{array}$ \\
\hline $2012 *$ Treatment & & $\begin{array}{c}0.017 \\
(0.009)^{*}\end{array}$ & & $\begin{array}{c}0.015 \\
(0.009)^{*}\end{array}$ & & $\begin{array}{c}0.015 \\
(0.009)^{*}\end{array}$ & & $\begin{array}{c}0.015 \\
(0.009)^{*}\end{array}$ \\
\hline $2013 *$ Treatment & & $\begin{array}{c}0.023 \\
(0.009)^{* *}\end{array}$ & & $\begin{array}{c}0.020 \\
(0.009)^{* *}\end{array}$ & & $\begin{array}{c}0.020 \\
(0.009)^{* *}\end{array}$ & & $\begin{array}{c}0.020 \\
(0.009)^{* *}\end{array}$ \\
\hline$R^{2}$ & 0.69 & 0.69 & 0.69 & 0.69 & 0.69 & 0.69 & 0.70 & 0.70 \\
\hline \# Insurers & 406 & 406 & 386 & 386 & 366 & 366 & 353 & 353 \\
\hline Observations & 3,295 & 3,295 & 3,224 & 3,224 & 3,125 & 3,125 & 3,049 & 3,049 \\
\hline
\end{tabular}

Note: The dependent variable in all columns is MLR. The column headings indicate the minimum number of observations required to determine treatment. All specifications include year fixed effects, insurer fixed effects, and a treatment group linear time trend. Regressions are weighted by enrollment, and standard errors are clustered by insurer. Treatment $\equiv \mathbb{1}\left\{\hat{d}_{i}>0\right\} .{ }^{*} \mathrm{p}<0.10, * * \mathrm{p}<0.05, * * * \mathrm{p}<.01$.

Table B.11: Regression Results: Group Market, Continuous Treatment using Different Observations to Determine Treatment

\begin{tabular}{|c|c|c|c|c|c|c|c|c|}
\hline & \multicolumn{2}{|c|}{1 Observation } & \multicolumn{2}{|c|}{2 Observations } & \multicolumn{2}{|c|}{3 Observations } & \multicolumn{2}{|c|}{4 Observations } \\
\hline & (1) & (2) & (3) & (4) & (5) & (6) & (7) & (8) \\
\hline Post-2011 * Treatment & $\begin{array}{c}0.523 \\
(0.123)^{* * *}\end{array}$ & & $\begin{array}{c}0.503 \\
(0.137)^{* * *}\end{array}$ & & $\begin{array}{c}0.500 \\
(0.139)^{* * *}\end{array}$ & & $\begin{array}{c}0.501 \\
(0.139)^{* * *}\end{array}$ & \\
\hline $2011 *$ Treatment & & $\begin{array}{c}0.464 \\
(0.117)^{* * *}\end{array}$ & & $\begin{array}{c}0.469 \\
(0.131)^{* * *}\end{array}$ & & $\begin{array}{c}0.463 \\
(0.132)^{* * *}\end{array}$ & & $\begin{array}{c}0.464 \\
(0.132)^{* * *}\end{array}$ \\
\hline $2012 *$ Treatment & & $\begin{array}{c}0.502 \\
(0.142)^{* * *}\end{array}$ & & $\begin{array}{c}0.482 \\
(0.163)^{* * *}\end{array}$ & & $\begin{array}{c}0.476 \\
(0.165)^{* * *}\end{array}$ & & $\begin{array}{c}0.475 \\
(0.165)^{* * *}\end{array}$ \\
\hline $2013 *$ Treatment & & $\begin{array}{c}0.634 \\
(0.146)^{* * *}\end{array}$ & & $\begin{array}{c}0.578 \\
(0.155)^{* * *}\end{array}$ & & $\begin{array}{c}0.584 \\
(0.157)^{* * *}\end{array}$ & & $\begin{array}{c}0.585 \\
(0.157)^{* * *}\end{array}$ \\
\hline$R^{2}$ & 0.70 & 0.70 & 0.69 & 0.69 & 0.70 & 0.70 & 0.70 & 0.70 \\
\hline \# Insurers & 406 & 406 & 386 & 386 & 366 & 366 & 353 & 353 \\
\hline Observations & 3,295 & 3,295 & 3,224 & 3,224 & 3,125 & 3,125 & 3,049 & 3,049 \\
\hline
\end{tabular}

Note: The dependent variable in all columns is MLR. The column headings indicate the minimum number of observations required to determine treatment. All specifications include year fixed effects, insurer fixed effects, and a treatment group linear time trend. Regressions are weighted by enrollment, and standard errors are clustered by insurer. Treatment $\equiv \hat{d}_{i} * \mathbb{1}\left\{\hat{d}_{i}>0\right\}$. ${ }^{*} \mathrm{p}<0.10,{ }^{* *} \mathrm{p}<0.05,{ }^{* * *} \mathrm{p}<.01$. 


\section{B.3 Instrumental Variables}

In this subsection, we implement an instrumental variables approach to further address concerns of regression to the mean, or more generally, measurement error in our treatment variable. In particular, we use data from 2006-2008 and data from 2009-2010 to separately predict whether an insurer will be treated by the new federal regulations that went into effect in 2011. To fix ideas, recall that our difference-in-differences treatment variable is $D_{i t} \equiv \mathbb{1}\left\{\hat{d}_{i}>0 ; t>2010\right\}$. Let $\hat{d}_{i}^{10}$ be a measure of $\hat{d}_{i}$ based on data from 2009 and 2010 and let $\hat{d}_{i}^{8}$ be a measure of $\hat{d}_{i}$ based on data from 2006 to 2008 . Then we have corresponding treatment variables $D_{i t}^{10}$ and $D_{i t}^{8}$ constructed with $\hat{d}_{i}^{10}$ and $\hat{d}_{i}^{8} \cdot{ }^{32}$ Because our predicted distance from the MLR threshold enters our primary estimating equation through both $D_{i t}$ and $t \mathbb{1}\left\{\hat{d}_{i}>0\right\}$, we need to instrument for both terms. We use $D_{i t}^{8}$ and $\mathbb{1}\left\{\hat{d}_{i}^{8}>0\right\}$ as instruments to estimate the following system of equations via two-stage least squares.

$$
\begin{aligned}
y_{i t} & =\gamma_{i}+\delta_{t}+\tau D_{i t}^{10}+\beta t \mathbb{1}\left\{\hat{d}_{i}^{10}>0\right\}+u_{i t} \\
D_{i t}^{10} & =\lambda_{i}+\lambda_{t}+\alpha_{1} D_{i t}^{8}+\alpha_{2} t \mathbb{1}\left\{\hat{d}_{i}^{8}>0\right\}+\eta_{i t} \\
t \mathbb{1}\left\{\hat{d}_{i}^{10}>0\right\} & =\widetilde{\lambda}_{i}+\widetilde{\lambda}_{t}+\widetilde{\alpha}_{1} D_{i t}^{8}+\widetilde{\alpha}_{2} t \mathbb{1}\left\{\hat{d}_{i}^{8}>0\right\}+\omega_{i t}
\end{aligned}
$$

The first stage results are shown for the individual market in Table B.12. As seen in column (1), predicted treatment based on 2006-2008 is closely and positively related to predicted treatment based on 2009-2010 data. Not surprisingly then, column (2) shows that the differential linear trend for our 2009-2010 predicted treatment group is also closely related to that for our 2006-2008 predicted treatment group. We find similar results, shown in the remaining columns of the table, for the instruments when we use our continuous treatment measures as well.

The instrumental variables results for the individual market with the binary treatment variable are presented in Table B.13. The results are quite similar to the corresponding OLS results in shown Table 3. The estimated impact of the federal regulation goes from a 7.3 percentage point increase in the MLR to an 8.3 percentage point increase; for claims, our OLS results indicate that the regulation increased claims by 6.8 percent while our IV estimates suggest a 9.6 percent increase. Our IV results do not suggest any impacts on premiums. Additional first stage and IV estimates for the group market and our continuous treatment measure can be found in Section B.3.1.

\footnotetext{
${ }^{32}$ As we saw in Tables B.4 through B.7, our estimated results using $D_{i t}$ and $D_{i t}^{10}$ are very similar.
} 
Table B.12: First Stage Results: Individual Market

\begin{tabular}{lcccc}
\hline & \multicolumn{2}{c}{ Binary treatment } & \multicolumn{2}{c}{ Continuous treatment } \\
\cline { 2 - 5 } & $D_{i t}^{10}$ & $t \mathbb{1}\left\{\hat{d}_{i}^{10}>0\right\}$ & $D_{i t}^{10}$ & $t \hat{d}_{i}^{10}$ \\
& $(1)$ & $(2)$ & $(3)$ & $(4)$ \\
\hline Post-2011 * Treatment & 0.529 & 0.035 & 0.497 & -3.231 \\
& $(0.077)^{* * *}$ & $(0.108)$ & $(0.164)^{* * *}$ & $(1.615)^{* *}$ \\
Post-2011 * Treatment * Year & -0.001 & 0.513 & -0.005 & 4.787 \\
& $(0.004)$ & $(0.087)^{* * *}$ & $(0.014)$ & $(0.748)^{* * *}$ \\
\hline F-test on instruments & 23.53 & 22.85 & 9.13 & 21.44 \\
\# Insurers & 184 & 184 & 184 & 184 \\
Observations & 1,311 & 1,311 & 1,311 & 1,311 \\
\hline
\end{tabular}

Note: Regressions are weighted by enrollment and standard errors are clustered by insurer. All specifications include year fixed effects and insurer fixed effects. The outcome variables are given in the column headings. Treatment $\equiv \mathbb{1}\left\{\hat{d}_{i}^{8}>0\right\}$ for columns (1) and (2); Treatment $\equiv \hat{d}_{i}^{8}$ for columns (3) and (4). ${ }^{*} \mathrm{p}<0.10, * *$ $\mathrm{p}<0.05, * * * \mathrm{p}<.01$.

\section{B.3.1 Additional Instrumental Variables Tables}


Table B.13: Instrumental Variables Results: Individual Market, Binary Treatment

\begin{tabular}{|c|c|c|c|c|c|c|}
\hline & \multicolumn{2}{|c|}{ MLR } & \multicolumn{2}{|c|}{$\ln$ (Claims) } & \multicolumn{2}{|c|}{$\ln ($ Premiums $)$} \\
\hline & (1) & $(2)$ & (3) & $(4)$ & (5) & (6) \\
\hline Post-2011 * Treatment & $\begin{array}{c}0.083 \\
(0.024)^{* * *}\end{array}$ & & $\begin{array}{c}0.096 \\
(0.042)^{* *}\end{array}$ & & $\begin{array}{l}-0.008 \\
(0.035)\end{array}$ & \\
\hline $2011 *$ Treatment & & $\begin{array}{c}0.078 \\
(0.023)^{* * *}\end{array}$ & & $\begin{array}{c}0.073 \\
(0.038)^{*}\end{array}$ & & $\begin{array}{l}-0.025 \\
(0.031)\end{array}$ \\
\hline $2012 *$ Treatment & & $\begin{array}{c}0.088 \\
(0.027)^{* * *}\end{array}$ & & $\begin{array}{c}0.121 \\
(0.048)^{* *}\end{array}$ & & $\begin{array}{c}0.011 \\
(0.040)\end{array}$ \\
\hline $2013 *$ Treatment & & $\begin{array}{c}0.093 \\
(0.035)^{* * *}\end{array}$ & & $\begin{array}{c}0.145 \\
(0.060)^{* *}\end{array}$ & & $\begin{array}{c}0.028 \\
(0.051)\end{array}$ \\
\hline \# Insurers & 184 & 184 & 184 & 184 & 184 & 184 \\
\hline Observations & 1,311 & 1,311 & 1,311 & 1,311 & 1,311 & 1,311 \\
\hline
\end{tabular}

Note: Regressions are weighted by enrollment and standard errors are clustered by insurer. All specifications include year fixed effects and insurer fixed effects. The outcome variables Claims and Premiums are measured on a per life-year basis. Treatment $\equiv \mathbb{1}\left\{\hat{d}_{i}^{8}>0\right\} .{ }^{*} \mathrm{p}<0.10,{ }^{* *} \mathrm{p}<0.05,{ }^{* * *} \mathrm{p}<.01$.

Table B.14: Instrumental Variables Results: Individual Market, Continuous Treatment

\begin{tabular}{|c|c|c|c|c|c|c|}
\hline & \multicolumn{2}{|c|}{ MLR } & \multicolumn{2}{|c|}{$\ln$ (Claims) } & \multicolumn{2}{|c|}{$\ln ($ Premiums $)$} \\
\hline & $(1)$ & $(2)$ & $(3)$ & $(4)$ & (5) & (6) \\
\hline Post-2011 * Treatment & $\begin{array}{c}0.579 \\
(0.197)^{* * *}\end{array}$ & & $\begin{array}{c}0.700 \\
(0.271)^{* * *}\end{array}$ & & $\begin{array}{c}-0.092 \\
(0.302)\end{array}$ & \\
\hline $2011 *$ Treatment & & $\begin{array}{c}0.518 \\
(0.192)^{* * *}\end{array}$ & & $\begin{array}{c}0.468 \\
(0.245)^{*}\end{array}$ & & $\begin{array}{l}-0.238 \\
(0.279)\end{array}$ \\
\hline $2012 *$ Treatment & & $\begin{array}{c}0.644 \\
(0.235)^{* * *}\end{array}$ & & $\begin{array}{c}0.961 \\
(0.329)^{* * *}\end{array}$ & & $\begin{array}{c}0.085 \\
(0.342)\end{array}$ \\
\hline $2013 *$ Treatment & & $\begin{array}{c}0.731 \\
(0.233)^{* * *}\end{array}$ & & $\begin{array}{c}1.310 \\
(0.416)^{* * *}\end{array}$ & & $\begin{array}{c}0.290 \\
(0.419)\end{array}$ \\
\hline \# Insurers & 184 & 184 & 184 & 184 & 184 & 184 \\
\hline Observations & 1,311 & 1,311 & 1,311 & 1,311 & 1,311 & 1,311 \\
\hline
\end{tabular}

Note: Regressions are weighted by enrollment and standard errors are clustered by insurer. All specifications include year fixed effects and insurer fixed effects. The outcome variables Claims and Premiums are measured on a per life-year basis. Treatment $\equiv \mathbb{1}\left\{\hat{d}_{i}^{8}>0\right\}$. ${ }^{*} \mathrm{p}<0.10,{ }^{* *} \mathrm{p}<0.05,{ }^{* * *} \mathrm{p}<.01$. 
Table B.15: Instrumental Variables Results: Group Market, Binary Treatment

\begin{tabular}{|c|c|c|c|c|c|c|}
\hline & \multicolumn{2}{|c|}{ MLR } & \multicolumn{2}{|c|}{$\ln ($ Claims $)$} & \multicolumn{2}{|c|}{$\ln ($ Premiums $)$} \\
\hline & (1) & $(2)$ & (3) & (4) & $(5)$ & (6) \\
\hline Post-2011 * Treatment & $\begin{array}{c}0.010 \\
(0.010)\end{array}$ & & $\begin{array}{c}0.046 \\
(0.033)\end{array}$ & & $\begin{array}{c}0.036 \\
(0.032)\end{array}$ & \\
\hline $2011 *$ Treatment & & $\begin{array}{c}0.011 \\
(0.009)\end{array}$ & & $\begin{array}{c}0.024 \\
(0.025)\end{array}$ & & $\begin{array}{c}0.013 \\
(0.023)\end{array}$ \\
\hline $2012 *$ Treatment & & $\begin{array}{c}0.007 \\
(0.012)\end{array}$ & & $\begin{array}{c}0.051 \\
(0.038)\end{array}$ & & $\begin{array}{c}0.044 \\
(0.035)\end{array}$ \\
\hline $2013 *$ Treatment & & $\begin{array}{c}0.016 \\
(0.013)\end{array}$ & & $\begin{array}{c}0.137 \\
(0.091)\end{array}$ & & $\begin{array}{c}0.120 \\
(0.088)\end{array}$ \\
\hline \# Insurers & 406 & 406 & 406 & 406 & 406 & 406 \\
\hline Observations & 3,125 & 3,125 & 3,125 & 3,125 & 3,125 & 3,125 \\
\hline
\end{tabular}

Note: Regressions are weighted by enrollment and standard errors are clustered by insurer. All specifications include year fixed effects and insurer fixed effects. The outcome variables Claims and Premiums are measured on a per life-year basis. Treatment $\equiv \mathbb{1}\left\{\hat{d}_{i}^{8}>0\right\} .{ }^{*} \mathrm{p}<0.10,{ }^{* *} \mathrm{p}<0.05,{ }^{* * *} \mathrm{p}<.01$.

Table B.16: First Stage Results: Group Market

\begin{tabular}{lcccc}
\hline & \multicolumn{2}{c}{ Binary treatment } & \multicolumn{2}{c}{ Continuous treatment } \\
\cline { 2 - 5 } & $D_{i t}^{10}$ & $t \mathbb{1}\left\{\hat{d}_{i}^{10}>0\right\}$ & $D_{i t}^{10}$ & $t \hat{d}_{i}^{10}$ \\
& $(1)$ & $(2)$ & $(3)$ & $(4)$ \\
\hline Post-2011 * Treatment & 0.504 & -0.032 & 0.438 & -0.217 \\
& $(0.055)^{* * *}$ & $(0.052)$ & $(0.076)^{* * *}$ & $(0.764)$ \\
Post-2011 * Treatment * Year & 0.002 & 0.526 & 0.001 & 7.309 \\
& $(0.002)$ & $(0.056)^{* * *}$ & $(0.002)$ & $(1.629)^{* * *}$ \\
\hline F-test on instruments & 45.87 & 45.80 & 16.88 & 16.33 \\
\# Insurers & 406 & 406 & 406 & 406 \\
Observations & 3,125 & 3,125 & 3,125 & 3,125 \\
\hline
\end{tabular}

Note: Regressions are weighted by enrollment and standard errors are clustered by insurer. All specifications include year fixed effects and insurer fixed effects. The outcome variables are given in the column headings. Treatment $\equiv \mathbb{1}\left\{\hat{d}_{i}^{8}>0\right\}$ for columns (1) and (2); Treatment $\equiv \hat{d}_{i}^{8}$ for columns (3) and (4). * $\mathrm{p}<0.10, * *$ $\mathrm{p}<0.05, * * * \mathrm{p}<.01$. 
Table B.17: Instrumental Variables Results: Group Market, Continuous Treatment

\begin{tabular}{|c|c|c|c|c|c|c|}
\hline & \multicolumn{2}{|c|}{ MLR } & \multicolumn{2}{|c|}{$\ln ($ Claims $)$} & \multicolumn{2}{|c|}{$\ln$ (Premiums) } \\
\hline & (1) & $(2)$ & $(3)$ & (4) & $(5)$ & (6) \\
\hline Post-2011 * Treatment & $\begin{array}{c}0.428 \\
(0.207)^{* *}\end{array}$ & & $\begin{array}{l}-0.407 \\
(0.873)\end{array}$ & & $\begin{array}{c}-0.915 \\
(0.778)\end{array}$ & \\
\hline $2011 *$ Treatment & & $\begin{array}{c}0.443 \\
(0.196)^{* *}\end{array}$ & & $\begin{array}{c}-0.444 \\
(0.683)\end{array}$ & & $\begin{array}{l}-0.977 \\
(0.618)\end{array}$ \\
\hline $2012 *$ Treatment & & $\begin{array}{c}0.376 \\
(0.271)\end{array}$ & & $\begin{array}{c}-0.559 \\
(1.074)\end{array}$ & & $\begin{array}{l}-0.998 \\
(0.918)\end{array}$ \\
\hline $2013 *$ Treatment & & $\begin{array}{c}0.506 \\
(0.247)^{* *}\end{array}$ & & $\begin{array}{c}0.238 \\
(1.880)\end{array}$ & & $\begin{array}{c}-0.342 \\
(1.780)\end{array}$ \\
\hline$R^{2}$ & 0.67 & 0.67 & 0.86 & 0.86 & 0.87 & 0.87 \\
\hline \# Insurers & 406 & 406 & 406 & 406 & 406 & 406 \\
\hline Observations & 3,125 & 3,125 & 3,125 & 3,125 & 3,125 & 3,125 \\
\hline
\end{tabular}

Note: Regressions are weighted by enrollment and standard errors are clustered by insurer. All specifications include year fixed effects and insurer fixed effects. The outcome variables Claims and Premiums are measured on a per life-year basis. Treatment $\equiv \mathbb{1}\left\{\hat{d}_{i}^{8}>0\right\} .{ }^{*} \mathrm{p}<0.10,{ }^{* *} \mathrm{p}<0.05,{ }^{* * *} \mathrm{p}<.01$. 


\section{B.4 Ancillary Results: Heterogeneity by Market Structure}

Table B.18: Heterogeneity Results by Market Structure: Individual Market, Cont. Treatment

\begin{tabular}{|c|c|c|c|c|c|c|}
\hline & \multicolumn{2}{|c|}{ MLR } & \multicolumn{2}{|c|}{$\ln$ (Claims) } & \multicolumn{2}{|c|}{$\ln ($ Premiums $)$} \\
\hline & $(1)$ & $(2)$ & $(3)$ & $(4)$ & $(5)$ & (6) \\
\hline Post-2011 * Treatment & $\begin{array}{c}0.820 \\
(0.169)^{* * *}\end{array}$ & $\begin{array}{c}0.620 \\
(0.175)^{* * *}\end{array}$ & $\begin{array}{c}1.241 \\
(0.409)^{* * *}\end{array}$ & $\begin{array}{c}0.512 \\
(0.612)\end{array}$ & $\begin{array}{l}-0.046 \\
(0.374)\end{array}$ & $\begin{array}{l}-0.476 \\
(0.589)\end{array}$ \\
\hline Post-2011 * Treatment $*$ MktShare & $\begin{array}{l}-0.214 \\
(0.223)\end{array}$ & & $\begin{array}{l}-0.933 \\
(0.584)\end{array}$ & & $\begin{array}{l}-0.458 \\
(0.534)\end{array}$ & \\
\hline Post- $2011 *$ Treatment $* H H I$ & & $\begin{array}{c}0.157 \\
(0.301)\end{array}$ & & $\begin{array}{c}0.389 \\
(1.130)\end{array}$ & & $\begin{array}{c}0.342 \\
(1.112)\end{array}$ \\
\hline Interaction var. mean & .2861 & .5282 & .2861 & .5282 & .2861 & .5282 \\
\hline$R^{2}$ & 0.75 & 0.75 & 0.89 & 0.89 & 0.86 & 0.86 \\
\hline \# Insurers & 184 & 184 & 184 & 184 & 184 & 184 \\
\hline Observations & 1,417 & 1,417 & 1,417 & 1,417 & 1,417 & 1,417 \\
\hline
\end{tabular}

Note: Regressions are weighted by enrollment, and standard errors are clustered by insurer. All specifications include year fixed effects, insurer fixed effects, and a treatment group linear time trend. The outcome variables Claims and Premiums are measured on a per life-year basis. HHI is divided by 10,000 so that the HHI variable ranges between 0 and 1 . Treatment $\equiv \mathbb{1}\left\{\hat{d}_{i}>0\right\}$. $* \mathrm{p}<0.10,{ }^{* *} \mathrm{p}<0.05,{ }^{* * *} \mathrm{p}<.01$.

Table B.19: Heterogeneity Results by Market Structure: Group Market, Binary Treatment

\begin{tabular}{|c|c|c|c|c|c|c|}
\hline & \multicolumn{2}{|c|}{ MLR } & \multicolumn{2}{|c|}{$\ln$ (Claims) } & \multicolumn{2}{|c|}{$\ln$ (Premiums) } \\
\hline & (1) & (2) & (3) & (4) & $(5)$ & (6) \\
\hline Post-2011* Treatment & $\begin{array}{c}0.028 \\
(0.010)^{* * *}\end{array}$ & $\begin{array}{c}0.026 \\
(0.012)^{* *}\end{array}$ & $\begin{array}{c}0.066 \\
(0.032)^{* *}\end{array}$ & $\begin{array}{c}0.093 \\
(0.038)^{* *}\end{array}$ & $\begin{array}{c}0.033 \\
(0.034)\end{array}$ & $\begin{array}{c}0.063 \\
(0.038)\end{array}$ \\
\hline Post-2011 * Treatment $*$ MktShare & $\begin{array}{c}-0.042 \\
(0.016)^{* * *}\end{array}$ & & $\begin{array}{l}-0.145 \\
(0.111)\end{array}$ & & $\begin{array}{l}-0.091 \\
(0.111)\end{array}$ & \\
\hline Post-2011 ${ }^{*}$ Treatment ${ }^{*} H H I$ & & $\begin{array}{l}-0.039 \\
(0.030)\end{array}$ & & $\begin{array}{l}-0.254 \\
(0.162)\end{array}$ & & $\begin{array}{l}-0.205 \\
(0.158)\end{array}$ \\
\hline Interaction var. mean & .1455 & .33 & .1455 & .33 & .1455 & .33 \\
\hline$R^{2}$ & 0.69 & 0.69 & 0.86 & 0.86 & 0.87 & 0.88 \\
\hline \# Insurers & 406 & 406 & 406 & 406 & 406 & 406 \\
\hline Observations & 3,295 & 3,295 & 3,295 & 3,295 & 3,295 & 3,295 \\
\hline
\end{tabular}

Note: Regressions are weighted by enrollment, and standard errors are clustered by insurer. All specifications include year fixed effects, insurer fixed effects, and a treatment group linear time trend. The outcome variables Claims and Premiums are measured on a per life-year basis. HHI is divided by 10,000 so that the HHI variable ranges between 0 and 1 . Treatment $\equiv \hat{d}_{i} * \mathbb{1}\left\{\hat{d}_{i}>0\right\} .{ }^{*} \mathrm{p}<0.10,{ }^{* *} \mathrm{p}<0.05, * * * \mathrm{p}<.01$. 
Table B.20: Heterogeneity Results by Market Structure: Group Market, Continuous Treatment

\begin{tabular}{|c|c|c|c|c|c|c|}
\hline & \multicolumn{2}{|c|}{ MLR } & \multicolumn{2}{|c|}{$\ln ($ Claims $)$} & \multicolumn{2}{|c|}{$\ln ($ Premiums $)$} \\
\hline & (1) & $(2)$ & $(3)$ & $(4)$ & $(5)$ & (6) \\
\hline Post-2011* Treatment & $\begin{array}{c}0.738 \\
(0.148) * * *\end{array}$ & $\begin{array}{c}0.509 \\
(0.193)^{* * *}\end{array}$ & $\begin{array}{c}1.704 \\
(0.989)^{*}\end{array}$ & $\begin{array}{c}2.486 \\
(1.744)\end{array}$ & $\begin{array}{c}0.730 \\
(1.067)\end{array}$ & $\begin{array}{c}1.830 \\
(1.712)\end{array}$ \\
\hline Post-2011 * Treatment $*$ MktShare & $\begin{array}{c}-0.854 \\
(0.381)^{* *}\end{array}$ & & $\begin{array}{l}-1.785 \\
(3.103)\end{array}$ & & $\begin{array}{l}-0.612 \\
(3.193)\end{array}$ & \\
\hline Post- $2011 *$ Treatment $* H H I$ & & $\begin{array}{c}0.048 \\
(0.516)\end{array}$ & & $\begin{array}{l}-4.410 \\
(4.890)\end{array}$ & & $\begin{array}{l}-4.493 \\
(4.735)\end{array}$ \\
\hline Interaction var. mean & .1455 & .33 & .1455 & .33 & .1455 & .33 \\
\hline$R^{2}$ & 0.70 & 0.70 & 0.86 & 0.87 & 0.87 & 0.88 \\
\hline \# Insurers & 406 & 406 & 406 & 406 & 406 & 406 \\
\hline Observations & 3,295 & 3,295 & 3,295 & 3,295 & 3,295 & 3,295 \\
\hline
\end{tabular}

Note: Regressions are weighted by enrollment, and standard errors are clustered by insurer. All specifications include year fixed effects, insurer fixed effects, and a treatment group linear time trend. The outcome variables Claims and Premiums are measured on a per life-year basis. HHI is divided by 10,000 so that the HHI variable ranges between 0 and 1 . Treatment $\equiv \hat{d}_{i} * \mathbb{1}\left\{\hat{d}_{i}>0\right\} . * \mathrm{p}<0.10,{ }^{* *} \mathrm{p}<0.05, * * * \mathrm{p}<.01$. 